\title{
The Cost of Human Capital Depreciation during Unemployment
}

\section{Lien Laureys ${ }^{1}$}

\author{
This version: July 2014
}

\begin{abstract}
Skill erosion during unemployment was of particular concern as unemployment duration increased in the Great Recession. I argue that it generates an externality in job creation: firms ignore how their hiring decisions affect the unemployment pool's skill composition, and hence the expected output produced by new hires. As a consequence, job creation is too low from a social point of view. But the extent to which it is too low varies over the cycle. This is because the externality's magnitude, which depends on the impact of job creation on the pool's skill composition, reduces when the share of unemployed workers who already have eroded skills increases.
\end{abstract}

Keywords: long-term unemployment, skill erosion, inefficiency

JEL Classification: E24, J24, J41, J64.

\footnotetext{
${ }^{1}$ Bank of England, Centre for Macroeconomics. Email: lien.laureys@ bankofengland.co.uk

The views expressed in this paper are those of the author, and not necessarily those of the Bank of England. This paper was written while the author was at Universitat Pompeu Fabra. I am especially grateful to Jordi Galí for his many helpful comments and guidance throughout. I would also like to thank Regis Barnichon, Vasco Carvalho, James Costain, Jan Eeckhout, Jonathan Heathcote, Timothy Kehoe, Christopher Pissarides, Edouard Schaal, Robert Shimer, Kjetil Storesletten, Thijs van Rens, participants of the CREI-macrobreakfast seminar, the Annual Search and Matching meeting 2012 in Cyprus, the macro group of the University of Warwick, and seminar participants at the Bank of Canada, the Bank of England, the European Central Bank, the Federal Reserve Board, HEC Paris, the London Business School, the University of Bonn, the University of Cologne, the University of Mannheim, Université de Montréal, Université du Quebec à Montréal, and the Riksbank for valuable comments and suggestions at various stages of this project. I am also grateful to the University of Minnesota for their hospitality while working on this project. I acknowledge financial support from the Spanish Ministry of Education. First version: March 2012
} 


\section{Introduction}

"...One concern we do have, of course, is the fact that more than 40 percent of the unemployed have been unemployed for six months or more. Those folks are either leaving the labor force or having their skills eroded. Although we haven't seen much sign of it yet, if that situation persists for much longer then that will reduce the human capital that is part of our growth process going forward."

(Ben Bernanke, 2012) ${ }^{2}$

The Great Recession has brought back the spectre of long-term unemployment. In the US the average unemployment duration has increased from an average of around 14 weeks in the period 1960-2007 to an average of close to 32 weeks in the period 2008-2013, a level unprecedented over the period from 1960 onwards. This increase has been of great concern to policy makers. One reason is the widely held belief that long unemployment spells lead to the depreciation of a worker's human capital which ultimately affects the economy's production potential. Empirical evidence also suggests that workers' human capital erodes during unemployment. ${ }^{3}$

But does the presence of skill loss during unemployment call for policy intervention? This paper looks at this issue through the lens of an otherwise standard random search model with aggregate uncertainty in which human capital depreciation during unemployment is introduced. Workers who had their skills eroded while being unemployed are less productive upon re-employment than workers whose skills were not affected. At the same time, I allow for learning-by-doing such that workers with eroded skills can regain their initial skill level while being employed.

In the presence of skill loss during unemployment, firms' hiring decisions do not only affect the unemployment rate but also the share of workers with eroded skills

\footnotetext{
${ }^{2}$ Question and answer session of the Senate Banking Committee hearing on the 1st of March 2012 with Federal Reserve chairman Ben Bernanke testifying on monetary policy and the US economy: http://www.reuters.com/article/2012/03/01/usa-fed-bernanke-idUSL2E8E13KI20120301.

${ }^{3}$ Addison and Portugal (1989), Gregory and Jukes (2001), Neal (1995), and Schmieder, von Wachter and Bender (2013) show that workers' re-employment wage is negatively affected by the length of their unemployment spell, while Edison and Gustavsson (2008) find that one year of unemployment duration reduces skills by an equivalent of 0.7 years of schooling. Keane and Wolpin (1997) provide evidence based on the estimation of a structural model.
} 
in the unemployment pool. Hiring influences workers' chance of finding a job, average unemployment duration, and thus the extent of skill erosion. The unemployment pool's skill composition determines how likely it is that job-seekers with or without eroded skills show up for job interviews. Consequently, firms' hiring decisions today, through their effect on job-seekers' human capital in the next period, affect the output that can be generated by other firms' new matches.

Comparing hiring decisions in the laissez-faire economy and the constrained-efficient economy reveals that human capital depreciation during unemployment is a source of inefficiency. This is the consequence of a composition externality related to job creation which arises in addition to the familiar congestion externality following from the search frictions. The composition externality arises because firms ignore how their hiring decisions today affect the unemployment pool's skill composition in the next period, and hence the expected productivity of other firms' new hires. Firms neglect that through hiring they prevent workers from being unemployed and exposed to skill erosion. At the same time, firms do not take into account that by employing a worker, this worker keeps her skills or regains her skills, and hence that there is an additional job-seeker without eroded skills when the match separates. In other words, when human capital depreciates during unemployment, there are gains from job creation which are not fully internalised.

Given that I assume that wages are set every period through Nash bargaining, I examine, in the spirit of Hosios (1990), if there exists a parameter condition for workers' bargaining power which restores efficiency. I find this is not the case when aggregate uncertainty is present and workers' bargaining power is constant across states.

To get a better understanding of the composition externality's magnitude, I look at which labour market policy can restore constrained-efficiency when this externality is the only source of inefficiency, besides the search frictions characterizing the labour market. I find that this policy takes the form of a state-dependent employment subsidy, which reflects that because of this externality job creation in the laissezfaire economy is always too low from a social point of view but not to the same extent. The reason why the social cost induced by this externality varies over the cycle can be understood when looking at its nature. 
First, the magnitude of the composition externality, and hence its welfare implications, hinges on the impact of today's job creation on the expected productivity of new hires. This impact reduces when the share of workers in the unemployment pool who already have eroded skills, and hence can no longer be prevented from skill erosion, increases. So how this externality's magnitude varies over the cycle depends on the dynamic path of human capital depreciation, as this will influence the point in the cycle at which this share starts to increase.

I study an environment where skill loss is bounded from below and workers' expected skills are decreasing and convex in their unemployment duration. ${ }^{4}$ In this environment, the optimal employment subsidy to offset this externality is procyclical, implying that the social cost induced by the composition externality is larger in booms than in recessions. This finding reflects that the impact of firms' hiring decisions on the composition of the pool is smaller in periods where the average unemployment duration is high. Note that also in periods with a low average unemployment duration the composition externality is at work because human capital depreciation during unemployment not only affects long-term but also short-term unemployed workers. The higher the average unemployment duration, the larger the share of unemployed workers who already have eroded skills, and hence are at a relatively flat part of their human capital profile. This reduces the extent to which hiring can prevent a further deterioration of the quality of the unemployment pool. Similarly, the externality's welfare costs increase in periods with a low average unemployment duration because the latter decreases the share of workers with eroded skills in the unemployment pool, and hence increases the impact of job creation on the pool's skill composition.

Second, the social cost induced by this externality also depends on workers' job finding probability because firms' hiring decisions only affect the output produced by a new match when the workers whose skills have been influenced by these hiring decisions actually find a job. So the lower the probability that unemployed workers are getting hired, the smaller the social gain from preventing them from losing their human capital, which reinforces the mechanism at play described in the previous

\footnotetext{
${ }^{4}$ Gregory and Jukes (2001) provide empirical evidence which is supportive of the skill loss profile assumed in this paper, but overall empirical evidence on the skill loss profile is scarce.
} 
paragraph.

Next, I analyse how the presence of skill loss during unemployment changes job creation relative to an economy without skill loss. Job creation, and hence labour market outcomes, are expected to change relative to an economy where the unemployed are not exposed to skill erosion because its presence affects the workers' and the firms' problem. But whether on average more or less jobs are created is not clear because of two opposing effects. On the one hand, the expected gain from job creation drops because the expected productivity of a new hire decreases relative to a world without skill loss. On the other hand, workers' outside option becomes worse when they face the possibility of losing some of their skills when being unemployed. This deterioration of their outside option leads to lower wages, which stimulates job creation. I find that the presence of skill loss can lower the average unemployment rate in the decentralized allocation. However, the unemployment rate is still too high from a social point of view because of the composition externality.

To shed light on the quantitative importance of the composition externality, I look at the extent to which labour market outcomes should change to reach constrainedefficiency. To calibrate the model to the US economy I make use of the model's prediction that workers' wages are on average negatively affected by the length of their unemployment spells, and the empirical evidence by Schmieder, von Wachter and Bender (2013) on the effect of unemployment duration on workers' wages. When skill loss is the only source of inefficiency, restoring constrained-efficiency entails a drop in the average unemployment rate in the range of 0.92 to 0.27 percentage points, indicating that the composition externality is quantitatively relevant.

Finally, I discuss how the presence of the composition externality depends on the search mechanism. I show that when workers with and without eroded skills search for jobs in separated markets, with each of those markets characterized by random search, and firms choose in which market to post vacancies, the decentralized allocation is constrained-efficient if the standard Hosios (1990) condition holds in each market. This is because the expected productivity of a new hire no longer depends on the unemployment pool's composition. 
This paper is related to three main strands in the literature. First, it relates to the literature looking at how skill erosion during unemployment affects labour market outcomes not only by showing the inefficiencies that can arise but also by emphasizing that the wage setting mechanism is key if one wants to understand how human capital depreciation during unemployment affects labour market outcomes. Pissarides (1992) has shown that skill loss can be a potential explanation for the observed persistence of unemployment fluctuations which has also been explored by EstebanPretel and Faraglia (2010). Furthermore, Ljungqvist and Sargent (1998) have found that the presence of skill loss, together with differences between welfare systems, is important to understand labour market outcomes in the US versus Europe. Related work has been done by den Haan et al. (2005) and Ljungqvist and Sargent (2004, 2007, 2008). Moreover, Pissarides (1992) has shown in a framework without aggregate uncertainty that multiple equilibria can arise when unemployed workers are exposed to skill loss. Additionally, Coles and Masters (2000) have argued that those multiple equilibria are Pareto rankable.

Second, this paper relates to the literature investigating whether the presence of human capital depreciation during unemployment should affect the design of policy. In contrast to this paper, which focuses on whether loss of skill affects the efficiency of aggregate labour market outcomes in the presence of risk neutral agents, the literature has focused in the first place on how policies providing insurance for riskaverse workers in an economy with incomplete markets are affected (see e.g. Pavoni (2009), Shimer and Werning (2006), Pavoni and Violante (2007), and Spinnewijn (2010)). Laureys (2014) analyses the implications of human capital depreciation during unemployment for optimal monetary policy.

Third, this paper relates to other papers in the literature that have shown that a composition externality arises when the pool of searchers is heterogeneous and search is random because the agents do not internalize how their decisions affect the quality of the matching possibilities of the other agents. In an environment with random search Burdett and Coles $(1997,1999)$ analyse the case of two-sided heterogeneity; Shimer and Smith (2001) discuss heterogeneous agents who have to decide about their search intensity; Albrecht, Navarro and Vroman (2010) discuss workers who are heterogeneous with respect to their market productivity and their participation 
decision is endogenous. In contrast to previous work, I explore the composition externality in an environment subject to aggregate shocks. Those shocks make the composition of the pool of searchers time-varying, which in turn allows me to analyse whether and how the externality's magnitude depends on the pool's composition.

The remainder of the paper is organized as follows. Section 2 describes the model. Section 3 compares the job creation decision in the decentralized and the constrainedefficient allocation. Next, section 4 explores whether constrained-efficiency can be attained through the wage setting mechanism, and which insights the optimal labour market policy can provide into the composition externality. Section 5 contains two exercises. The first exercise shows how labour market outcomes in the presence of skill loss change relative to an economy without skill loss. In the second exercise, the model is calibrated to the US economy and it is analysed what the quantitative importance of the composition externality is by looking at the extent to which labour market outcomes should change to attain constrained-efficiency. Section 6 discusses the implications of some important assumptions of the model. Finally, section 7 concludes.

\section{The Economy}

The model is an extension of a discrete-time search and matching model à la DiamondMortensen-Pissarides with aggregate uncertainty. In this framework unemployed workers face the risk of losing some of their human capital, making them less productive upon re-employment. ${ }^{5}$ The longer the unemployment spell, the more likely a worker has eroded skills. At the same time the model allows for learning-by-doing such that workers can regain their human capital while being employed. ${ }^{6}$

\footnotetext{
${ }^{5}$ This framework abstracts from firm specific human capital. Therefore, workers only face the risk of losing some of their human capital while being unemployed and not when the match separates.

${ }^{6}$ In what follows I use the term "skill" and "human capital" interchangeably.
} 


\subsection{Population and Technology}

There is a continuum of infinitely-lived, risk-neutral workers on the unit interval. These workers maximize their expected discounted utility, which is defined over consumption and home production. Employed workers earn a wage $w^{i}$ depending on their skills, whereas unemployed workers engage in home production which generates a value $b$. The latter can be thought of as the opportunity cost of working and is assumed to be the same for all workers.

Workers are heterogeneous in their skills because skill erosion during unemployment and learning-by-doing on the job makes workers' human capital depend on their employment history. To keep the analysis simple, workers' human capital can only take two values, and is either high $(\mathrm{H})$ or low $(\mathrm{L})$. A worker's skills determine her productivity: high-skilled workers have high productivity, whereas low-skilled workers have low productivity. The transition between skill types occurs as follows. In each period, an unemployed high-skilled worker becomes low-skilled with probability $l \in(0,1]$. Thus the longer a worker's unemployment duration, the larger the chance that her human capital has depreciated. At the same time, when being low-skilled, she can regain her productivity while being employed through learning-by-doing. In each period, an employed low-skilled worker becomes highskilled with probability $g \in(0,1]$.

A large measure of risk-neutral, profit-maximizing firms employs workers. As is standard in the literature, each firm consists of a single-worker production unit. Its output depends on the worker's human capital and aggregate productivity $A$. The latter follows the process

$$
\log (A)=\rho_{a} \log \left(A_{-1}\right)+\varepsilon
$$

where $\varepsilon$ is an iid shock. Given the production technology, output produced by matches with a high and low-skilled worker is determined by equations (2) and (3) respectively

$$
\begin{gathered}
y^{H}(A)=A \\
y^{L}(A)=(1-\delta) A
\end{gathered}
$$


where the skill level of a high-skilled worker is normalized to one, and that of a lowskilled worker is defined by $1-\delta$. The parameter $\delta \in[0,1)$ can be interpreted as the rate of human capital depreciation. When $\delta \in(0,1)$ skill erosion is present, making some workers less productive upon re-employment. ${ }^{7}$ When $\delta=0$, the model boils down to the standard model.

\subsection{Labour Market}

The labour market is characterized by random search à la Diamond-MortensenPissarides. I assume that all workers search in the same market. Thus when a firm opens a vacancy at cost $\kappa>0$, both workers with and without eroded skills can apply for the job opening. Since a firm meets at most one worker at each round of interviews, which is a standard assumption in this class of models, all interviews lead to successful hiring as long as the match surplus is non-negative. In every period, the total number of interviews in the economy is determined by a matching function. This function is strictly increasing and concave in both arguments and displays constant returns to scale. It is given by

$$
m(v, u)=B v^{1-\xi} u^{\xi}
$$

where $B$ represents the efficiency of the matching process, $1-\xi$ is the elasticity of vacancies where $\xi \in(0,1), v$ is the total number of vacancies posted by firms, and $u$ is the total number of job-seekers weighted by their search effectiveness. Because I assume that unemployment duration does not affect workers' search effectiveness, and normalizing search effectiveness to one, the relevant measure of job-seekers in the matching function is given by the total number of unemployed $u$. The latter is

\footnotetext{
7 The interpretation that workers who have suffered from human capital depreciation during unemployment are less productive upon re-employment has also been used by Pissarides (1992). Alternatively, Coles and Masters (2000) and Esteban-Pretel and Faraglia (2010) assume that these workers are equally productive as workers without skill loss once a fixed training cost has been paid.
} 
defined as the sum of high-skilled $\left(u^{H}\right)$ and low-skilled $\left(u^{L}\right)$ unemployed

$$
u \equiv u^{H}+u^{L}
$$

Labour market tightness is defined as $\theta(x) \equiv \frac{v(x)}{u(x)}$, where $x$ denotes the state of the economy and is defined below. The probability for a firm posting a vacancy to meet a job-seeker is defined as

$$
q(\theta(x)) \equiv \frac{m(v(x), u(x))}{v(x)}=B \theta(x)^{-\xi}
$$

where $q(\theta(x))$ is decreasing in labour market tightness. The probability that a jobseeker gets a job interview is given by

$$
p(\theta(x)) \equiv \frac{m(v(x), u(x))}{u(x)}=B \theta(x)^{1-\xi}
$$

where $p(\theta(x))$ is increasing in labour market tightness. The job finding probability is the same for both worker types because unemployment duration has no effect on search effectiveness. When the match surplus is non-negative for both skill types, workers also have the same hiring probability.

Timing. At the beginning of the period, a shock to aggregate productivity $A$ is realized. After observing the economy's state, firms post vacancies and hire workers. Next, production takes place using both the existing and newly hired workers. After production some workers' type changes: unemployed high-skilled workers become low-skilled with probability $l$, and employed low-skilled workers become highskilled with probability $g$. Next exogenous separation takes place, and a fraction $\gamma$ of the matches breaks up. ${ }^{8}$

Labour market flows and the economy's state. The unemployment pool's heterogeneity affects the economy's state $x$ compared to the standard model. In addition

\footnotetext{
${ }^{8}$ The timing assumption in this model is standard in the business cycle literature, see e.g. Blanchard and Galí (2010). The difference compared to the standard DMP setting is that newly hired workers become productive immediately upon hiring.
} 
to aggregate productivity $A$, the number of vacancies posted by firms also depends on the fraction of low-skilled job-seekers in the unemployment pool. The latter is given by

$$
s(x) \equiv \frac{u^{L}(x)}{u(x)}
$$

The number of high and low-skilled job-seekers evolve according to

$$
\begin{gathered}
u^{H}(x)=(1-l) \tilde{u}_{-1}^{H}+\gamma\left(n^{H}\left(x_{-1}\right)+g n_{-1}^{L}\right) \\
u^{L}(x)=\tilde{u}_{-1}^{L}+l \tilde{u}_{-1}^{H}+\gamma(1-g) n_{-1}^{L}
\end{gathered}
$$

where $\tilde{u}^{i}$ are the job-seekers of type $i=\{H, L\}$ who remain unemployed after hiring takes place $\tilde{u}^{i} \equiv(1-p(\theta(x))) u^{i}(x)$, and $n^{i}$ is the number of workers of type $i$ employed in a given period. Equation (8) shows that the high-skilled job-seekers are all previous period's unemployed high-skilled workers who have not lost their skills, and all the high-skilled workers who just got fired. The latter consists on the one hand of those who were operating in the previous period as high-skilled workers, and on the other hand of those who were low-skilled but regained their skills because of learning-by-doing. Similarly, equation (9) shows that the low-skilled jobseekers are last period's unemployed low-skilled workers and high-skilled workers who have lost some of their skills, and all the low-skilled workers who were employed last period but did not regain skills and just lost their job.

High-skilled and low-skilled employment are given by

$$
\begin{gathered}
n^{H}(x)=(1-\gamma)\left[n^{H}\left(x_{-1}\right)+g n_{-1}^{L}\right]+p(\theta(x)) u^{H}(x) \\
n^{L}=(1-\gamma)(1-g) n_{-1}^{L}+p(\theta(x)) u^{L}(x)
\end{gathered}
$$

So high-skilled employment is given by the high-skilled and low-skilled employees with regained skills who kept their job, and the high-skilled new hires. Similarly, the low-skilled employed are on the one hand those who did neither regain skills nor got fired, and on the other hand the newly hired low-skilled unemployed.

Given the labour market flows, keeping track of the fraction of low-skilled workers in the unemployment pool (equation (7)), implies keeping track of the distribu- 
tion of worker types across employment states. But, when taking into account the definition of the total labour force, it can be seen that either the number of high or low-skilled unemployed after hiring takes place $\left(\tilde{u}^{i}\right)$ or the number of high or low-skilled employed $\left(n^{i}\right)$ can be expressed as a function of the other three. Normalizing the total size of the labour force to one and abstracting from labour force participation decisions gives

$$
1=\tilde{u}^{H}+\tilde{u}^{L}+n^{L}+n^{H}(x)
$$

As a result, workers and firms can keep track of the composition of the pool of job-seekers, by for example keeping track of $\tilde{u}^{H}, \tilde{u}^{L}$ and $n^{L}$. Therefore, the economy's state is given by $x=\left\{A, \tilde{u}_{-1}^{H}, \tilde{u}_{-1}^{L}, n_{-1}^{L}\right\}$, where the law of motions of the endogenous state variables $\tilde{u}_{-1}^{H}, \tilde{u}_{-1}^{L}, n_{-1}^{L}$ are given by

$$
\begin{gathered}
\tilde{u}^{H}=(1-p(\theta(x)))\left[(1-l) \tilde{u}_{-1}^{H}+\gamma\left(1-(1-g) n_{-1}^{L}-\tilde{u}_{-1}^{H}-\tilde{u}_{-1}^{L}\right)\right] \\
\tilde{u}^{L}=(1-p(\theta(x)))\left[\tilde{u}_{-1}^{L}+l \tilde{u}_{-1}^{H}+\gamma(1-g) n_{-1}^{L}\right] \\
n^{L}=(1-\gamma)(1-g) n_{-1}^{L}+p(\theta(x))\left[\tilde{u}_{-1}^{L}+l \tilde{u}_{-1}^{H}+\gamma(1-g) n_{-1}^{L}\right]
\end{gathered}
$$

\subsection{Firm's Problem}

The firm's value of employing a high and a low-skilled worker respectively, is given by

$$
\begin{gathered}
J^{H}(x)=y^{H}(A)-w^{H}(x)+(1-\gamma) \beta E_{x}\left\{J^{H}\left(x^{\prime}\right)\right\} \\
J^{L}(x)=y^{L}(A)-w^{L}(x)+(1-\gamma) \beta E_{x}\left\{g J^{H}\left(x^{\prime}\right)+(1-g) J^{L}\left(x^{\prime}\right)\right\}
\end{gathered}
$$

where $\beta \in(0,1)$ represents the discount factor. The firm's value of employing a worker depends on the generated output $y^{i}(A)$ with $i=\{H, L\}$, the wage cost $w^{i}(x)$, where wages are set through Nash bargaining as discussed in section 2.5 , and the continuation value of the match.

The firm's value of posting a vacancy is given by

$V(x)=-\kappa+q(\theta(x))\left[(1-s(x)) J^{H}(x)+s(x) J^{L}(x)\right]+(1-q(\theta(x))) \beta E_{x}\left\{V\left(x^{\prime}\right)\right\}$ 
When imposing the free-entry condition $V(x)=0$, the above equation becomes

$$
\frac{\kappa}{q(\theta(x))}=(1-s(x)) J^{H}(x)+s(x) J^{L}(x)
$$

This reflects that firms create jobs such that the expected hiring cost (LHS) equals the expected gain of hiring (RHS). The latter is a function of the unemployment pool's composition because the composition determines the probability that a jobseeker of a particular type shows up for the job interview.

\subsection{Worker's Problem}

A high and low-skilled worker's value of being employed respectively, is given by

$$
\begin{gathered}
W^{H}(x)=w^{H}(x)+\beta E_{x}\left\{\left(1-\gamma+\gamma p\left(\theta\left(x^{\prime}\right)\right)\right) W^{H}\left(x^{\prime}\right)+\gamma\left(1-p\left(\theta\left(x^{\prime}\right)\right)\right) U^{H}\left(x^{\prime}\right)\right\} \\
W^{L}(x)=w^{L}(x)+\beta E_{x}\left\{\begin{array}{c}
\left(1-\gamma+\gamma p\left(\theta\left(x^{\prime}\right)\right)\right)\left[g W^{H}\left(x^{\prime}\right)+(1-g) W^{L}\left(x^{\prime}\right)\right] \\
+\gamma\left(1-p\left(\theta\left(x^{\prime}\right)\right)\right)\left[g U^{H}\left(x^{\prime}\right)+(1-g) U^{L}\left(x^{\prime}\right)\right]
\end{array}\right\}
\end{gathered}
$$

For both worker types, this value depends on the wage and the continuation value. The latter is made up of three parts. First, with probability $1-\gamma$ the match survives separation and the worker continues working at the same firm. Because of learningby-doing a worker who was low-skilled will now be high-skilled with probability $g$. Second, with probability $\gamma$ the match breaks up, and the worker finds a new job with probability $p(\theta)$. Note that given that the worker gets hired in the same period, a high-skilled worker's skills will not have yet been exposed to skill erosion, and hence she continues producing as a high-skilled worker. Third, with probability $\gamma$ the match breaks up, and the worker remains unemployed with probability $1-$ $p(\theta)$, giving her the value $U^{i}$. A high and low-skilled worker's value of being 
unemployed respectively, is given by

$$
\begin{gathered}
U^{H}(x)=b+\beta E_{x}\left\{\begin{array}{r}
l\left[p\left(\theta\left(x^{\prime}\right)\right) W^{L}\left(x^{\prime}\right)+\left(1-p\left(\theta\left(x^{\prime}\right)\right)\right) U^{L}\left(x^{\prime}\right)\right] \\
+(1-l)\left[p\left(\theta\left(x^{\prime}\right)\right) W^{H}\left(x^{\prime}\right)+\left(1-p\left(\theta\left(x^{\prime}\right)\right)\right) U^{H}\left(x^{\prime}\right)\right]
\end{array}\right\} \\
U^{L}(x)=b+\beta E_{x}\left\{p\left(\theta\left(x^{\prime}\right)\right) W^{L}\left(x^{\prime}\right)+\left(1-p\left(\theta\left(x^{\prime}\right)\right)\right) U^{L}\left(x^{\prime}\right)\right\}
\end{gathered}
$$

It depends on the value of home production $b$, and the probability of finding a job next period. The high-skilled workers also take into account the probability that they will have lost their human capital by the time they can search again for jobs.

Both the value function of being employed and unemployed show that workers take into account that in the presence of skill erosion during unemployment and learning-by-doing their employment status affects their skills.

\subsection{Wages}

Wages are renegotiated in every period. Following the literature, I assume generalized Nash bargaining between a worker and firm. Consequently, total match surplus is split between the worker and the firm so that each of them gets a fraction of the total match surplus given by their bargaining power parameter. Defining total match surplus as $M^{i}(x) \equiv W^{i}(x)-U^{i}(x)+J^{i}(x)$, the surplus for a worker and a firm of being in a match is given by ${ }^{9}$

$$
\begin{gathered}
W^{i}(x)-U^{i}(x)=\eta M^{i}(x) \\
J^{i}(x)=(1-\eta) M^{i}(x)
\end{gathered}
$$

where $\eta$ and $1-\eta$ measure respectively the workers' and firms' bargaining power. The solution to the Nash bargaining problem leads to the following expression for the wage of a worker of type $i$

$$
w^{i}(x)=\eta y^{i}(x)+(1-\eta) \mathscr{O}^{i}(x)
$$

\footnotetext{
${ }^{9}$ Note that the surplus for a firm from being in a match equals the value of having a worker employed because free-entry drives the value of having a vacancy to zero.
} 
where the outside option $\mathscr{O}^{i}$ for a worker of type $i$ of being in a match, is given by

$$
\begin{gathered}
\mathscr{O}^{H}(x) \equiv b+\beta E_{x}\left\{\begin{array}{c}
\eta p\left(\theta\left(x^{\prime}\right)\right)\left[(1-l-\gamma) M^{H}\left(x^{\prime}\right)+l M^{L}\left(x^{\prime}\right)\right] \\
-l\left[U^{H}\left(x^{\prime}\right)-U^{L}\left(x^{\prime}\right)\right]
\end{array}\right\} \\
\mathscr{O}^{L}(x) \equiv b+\beta E_{x}\left\{\begin{array}{c}
\eta p\left(\theta\left(x^{\prime}\right)\right)\left[(1-\gamma(1-g)) M^{L}\left(x^{\prime}\right)-\gamma g M^{H}\left(x^{\prime}\right)\right] \\
-g\left[U^{H}\left(x^{\prime}\right)-U^{L}\left(x^{\prime}\right)\right]
\end{array}\right\}
\end{gathered}
$$

The outside option reflects that being in a match today implies that a worker cannot engage in home production $b$ today and cannot search for another job in the next period unless the match separates. The high-skilled worker's outside option also reflects that if she had not been employed, she would have faced the chance of losing some of her human capital, and hence becoming a low-skilled job-seeker. At the same time, workers keep in mind that being employed today might affect their type, and hence might change their new employment prospects in case the match separates in the next period. In particular, a high-skilled worker takes into account that being employed today guarantees that she keeps her productivity, whereas a low-skilled worker takes into account that being employed today might lead her to regain her productivity and hence be able to search as a high-skilled worker when the match separates.

The expression for the wages (equation (22)) reveals that the presence of human capital depreciation during unemployment not only affects the low-skilled worker's wage but also the high-skilled worker's wage. The latter is affected because human capital depreciation during unemployment influences the high-skilled worker's outside option: the high-skilled worker takes into account that part of her outside option is searching for a job as a low-skilled worker (see expression (23)). 


\subsection{Equilibrium}

In equilibrium, the surplus from a match with a high and low-skilled worker respectively, is given by

$$
\begin{gathered}
M^{H}(x)=y^{H}(A)-b+\beta E_{x}\left\{\begin{array}{c}
\left(1-\gamma+\eta \gamma p\left(\theta\left(x^{\prime}\right)\right)\right) M^{H}\left(x^{\prime}\right) \\
-\eta p\left(\theta\left(x^{\prime}\right)\right)\left[l M^{L}\left(x^{\prime}\right)+(1-l) M^{H}\left(x^{\prime}\right)\right] \\
+l\left[U^{H}\left(x^{\prime}\right)-U^{L}\left(x^{\prime}\right)\right]
\end{array}\right\} \\
M^{L}(x)=y^{L}(A)-b+\beta E_{x}\left\{\begin{array}{c}
\left(1-\gamma+\eta \gamma p\left(\theta\left(x^{\prime}\right)\right)\right)\left[g M^{H}\left(x^{\prime}\right)+(1-g) M^{L}\left(x^{\prime}\right)\right] \\
-\eta p\left(\theta\left(x^{\prime}\right)\right) M^{L}\left(x^{\prime}\right)+g\left[U^{H}\left(x^{\prime}\right)-U^{L}\left(x^{\prime}\right)\right]
\end{array}\right\}
\end{gathered}
$$

and where

$$
\begin{gathered}
U^{H}(x)=b+\beta E_{x}\left\{\begin{array}{c}
\eta p\left(\theta\left(x^{\prime}\right)\right)\left[(1-l) M^{H}\left(x^{\prime}\right)+l M^{L}\left(x^{\prime}\right)\right] \\
+(1-l) U^{H}\left(x^{\prime}\right)+l U^{L}\left(x^{\prime}\right)
\end{array}\right\} \\
U^{L}(x)=b+\beta E_{x}\left\{\eta p\left(\theta\left(x^{\prime}\right)\right) M^{L}\left(x^{\prime}\right)+U^{L}\left(x^{\prime}\right)\right\}
\end{gathered}
$$

The expressions (25) and (26) are obtained from combining the firms' and workers' value functions for the high and low-skilled workers respectively (equations (13), (14), (16), (17), (18), and (19)) with the wage setting rule (equations (20) and (21)). The expressions (27) and (28) are obtained from combining the value of being unemployed (equations (18) and (19)) with the wage setting rule (equation (20)).

The equilibrium vacancy creation condition follows from combining the job creation equation and the wage setting rule (equation (15) and (21) respectively), and is given by

$$
\frac{\kappa}{q(\theta(x))}=(1-\eta)\left[(1-s(x)) M^{H}(x)+s(x) M^{L}(x)\right]
$$

Definition 1. For a given state of the economy $x=\left\{A, \tilde{u}_{-1}^{H}, \tilde{u}_{-1}^{L}, n_{-1}^{L}\right\}$, this economy's equilibrium consists of a value for labour market tightness $\theta(x)$ which satisfies the vacancy creation condition (equation (29)), given the surplus from a match with a high-skilled and low-skilled worker respectively (equations (25) and (26)), and taking into account the expressions for the job filling and finding probab- 
ility (equations (5) and (6)). Given this period's state and the equilibrium value of labour market tightness, next period's state is determined by the law of motions for the endogenous state variables (equation (10), (11), and (12)), the law of motion for aggregate technology (equation (1)), and the realization of the shock to aggregate technology $\varepsilon$.

\section{Skill Erosion as a Source of Inefficiency}

Throughout this section and section 4, I focus on the special case where $g=l=1$. This implies that a low-skilled worker's productivity is restored with probability 1 after having worked for one period, and a high-skilled worker's human capital deteriorates with probability 1 after having been out of work for one period. The latter implies that human capital depreciation during unemployment can only be avoided when a worker who loses her job in a given period finds a new one during that same period. The reason for focusing on this specific case is because it allows me to derive analytical expressions which provide insights into this economy. This in turn follows from the size of the economy's state being reduced.

The number of high and low-skilled job-seekers respectively is now defined as $u^{H}\left(n_{-1}\right)=\gamma n_{-1}$ and $u^{L}\left(n_{-1}\right)=1-n_{-1}$, where $n$ represents total employment, which is defined as $n \equiv n^{H}+n^{L}$ and evolves according to

$$
n=(1-\gamma) n_{-1}+p(\theta(x))\left(1-(1-\gamma) n_{-1}\right)
$$

Both the number of high and low-skilled job-seekers can now be written as a function of previous period's employment, and hence so can be the fraction of lowskilled job-seekers in the unemployment pool. Consequently, the economy's state is now given by $x=\left\{A, n_{-1}\right\}$.

\subsection{Constrained-Efficient Allocation}

The social planner is subject to the same technological constraints, the same pattern of losing and regaining skills, and the same labour market frictions as in the 
decentralized economy. The social planner's problem consists of choosing the optimal amount of jobs to create such that the utility of the representative worker is maximized. Given workers' risk neutrality, this coincides with maximizing total output net of vacancy posting costs.

The planner's problem is given by

$$
V^{P}(x)=\max _{\theta}\left[\begin{array}{l}
y^{H}(A) n^{H}(x)+y^{L}(A) n^{L}(x)-\kappa \theta(x)\left(1-(1-\gamma) n_{-1}\right) \\
+b(1-n)+\beta E_{x}\left\{V^{P}\left(x^{\prime}\right)\right\}
\end{array}\right]
$$

subject to the process for aggregate technology (equation (1)), and the law of motion for the endogenous state variable employment (equation (30)), where $n^{H}(x)=(1-$ $\gamma) n_{-1}+B \theta(x)^{1-\xi} \gamma n_{-1}$ and $n^{L}(x)=B \theta(x)^{1-\xi}\left(1-n_{-1}\right)$. Note that the relevant state for the social planner $(x)$ is the same as in the decentralized allocation $x=$ $\left\{A, n_{-1}\right\} \cdot{ }^{10}$

Solving the social planner's problem gives the following expression for job creation in the constrained-efficient allocation ${ }^{11}$

$$
\frac{\kappa}{q(\theta(x))}=(1-\xi)\left[\bar{y}(x)-b+\beta E_{x}\left\{\Lambda^{P}\left(x^{\prime}\right)\right\}\right]
$$

where $\bar{y}(x) \equiv\left(1-s\left(n_{-1}\right)\right) y^{H}(A)+s\left(n_{-1}\right) y^{L}(A)$ represents the expected output of a new hire, and $\Lambda^{P}$ represents the continuation value of the match and is given by

$$
\Lambda^{P}(x) \equiv \Lambda_{1}^{P}(x)+\Lambda_{2}^{P}(x)+\Lambda_{3}^{P}(x)
$$

\footnotetext{
${ }^{10}$ This follows from the assumption that new hires become productive upon hiring in combination with the parameter restriction $l=g=1$. Those conditions imply that the fraction of low-skilled searchers can be expressed as a function of last period's employment, and that all employed workers will be high-skilled by the time the planner has to decide again about optimal job creation. As a result, keeping track of how many workers are employed is sufficient to know the employed workers' quality. If production in a given period were to take place with both last period's employed and last period's new hires, the planner would also have to keep track of the quality of last period's new hires, since the low-skilled would not have been able yet to regain their productivity. Therefore, even though the planner needs to keep track of the total number of high and low-skilled employed workers in addition to the share of low-skilled job-seekers in the unemployment pool, this can still be done just be keeping track of last period's total employment.

${ }^{11}$ See Appendix A.1 for more details about the derivation.
} 
where

$$
\begin{gathered}
\Lambda_{1}^{P}(x) \equiv(1-\gamma)\left(\frac{\kappa}{q(\theta(x))(1-\xi)}+y^{H}(A)-\bar{y}(x)\right) \\
\Lambda_{2}^{P}(x) \equiv p(\theta(x))\left[\gamma\left(\frac{\kappa}{q(\theta(x))(1-\xi)}+y^{H}(A)-\bar{y}(x)\right)-\left(\frac{\kappa}{q(\theta(x))(1-\xi)}+y^{L}(A)-\bar{y}(x)\right)\right] \\
\Lambda_{3}^{P}(x) \equiv(1-\gamma)(1-\xi) p(\theta(x))\left(\frac{\kappa}{q(\theta(x))(1-\xi)}\right)
\end{gathered}
$$

Job creation (equation (31)) is such that the expected hiring cost (LHS) equals the expected gain from job creation (RHS). As in the standard model, the expected hiring cost depends on the vacancy posting cost $\kappa$ and the vacancy filling probability $q(\theta)$. The expected gain from job creation depends on the expected output produced by the new hire $\bar{y}$, the loss in home production $b$, and the continuation value of the match (equation (32)) which can be split up in three terms discussed in more detail below. 12

The continuation value's first term $\left(\Lambda_{1}^{P}\right)$ captures the value when the match continues producing: creating a job today guarantees that next period a match will be operating with a high-skilled worker if this match does not separate. The value of a match with a high-skilled worker is given by the savings in expected hiring $\operatorname{costs}^{13}$, and a term representing the output gain of employing a high-skilled worker. There is an output gain related to employing a specific worker type because a new hire would not necessarily be of the same type but an average job-seeker from the unemployment pool. ${ }^{14}$ Therefore, the expected output gain realized next period from hiring a worker today is defined as the output generated by this worker $\left(y^{H}\right)$ relative to the expected output of a new hire which depends on the composition of the $\operatorname{pool}(\bar{y})$.

The second term $\left(\Lambda_{2}^{P}\right)$ represents the worker's outside option and reflects that today's job creation affects next period's output through its influence on the com-

\footnotetext{
${ }^{12}$ The expected gain from job creation is weighted by $1-\xi$ because the planner takes into account how posting an additional vacancy affects today's vacancy filling probability.

${ }^{13}$ The savings in expected hiring costs depend on the vacancy posting cost and the vacancy filling probability weighted by $(1-\xi)$ because the planner takes into account the effect on the vacancy filling probability that would be caused by posting an additional vacancy: $\frac{\partial q(\theta)}{\partial v}=-\xi \frac{q(\theta)}{v}$

${ }^{14}$ When workers are homogeneous the value of a match equals the savings in expected hiring costs because an employee can be replaced by an identical worker when paying this cost.
} 
position of next period's unemployment pool. First, in case of separation there will be a high-skilled worker searching for a job, following from employment allowing a worker to regain or keep her productivity. The planner takes into account that when this worker finds a new job in the same period, which happens with probability $p(\theta)$, a high-skilled match starts operating leading to an output gain $\left(y^{H}-\bar{y}>0\right)$. Second, employment prevents a worker from losing skills. If the worker had been unemployed, she would have lost skills or remained low-skilled. The planner takes into account that if this now low-skilled worker had found a job, which would have happened with probability $p(\theta)$, this worker would have produced $y^{L}$ whereas if another worker had been hired, the expected output would have been $\bar{y}$, creating an output loss $\left(y^{L}-\bar{y}<0\right)$. The prospect of skill loss when not being employed lowers the worker's outside option, and hence increases the continuation value of a match.

The third term $\left(\Lambda_{3}^{P}\right)$ reflects the positive congestion effect induced by having a jobseeker less when the match survives separation, making it easier for the other job seekers to get hired. ${ }^{15}$ The value generated by this positive effect is expressed as the value of a match with an average worker, which is given by the expected hiring cost. This follows from a change in labour market tightness affecting each worker's hiring probability in exactly the same way because it is independent of her type. ${ }^{16}$

\subsection{Constrained-Efficient versus Decentralized Allocation}

To detect whether skill erosion during unemployment is a source of inefficiency I compare the job creation decision in the decentralized and the constrained-efficient allocation under the standard Hosios (1990) condition. This condition sets workers' bargaining power $(\eta)$ equal to the elasticity of unemployment in the matching function $(\xi)$. The reason for doing so is because in the absence of skill erosion the decentralized allocation is constrained-efficient when the standard Hosios condition holds. This follows from the congestion externality being internalized when

\footnotetext{
${ }^{15}$ Note that $-\frac{\partial p(\theta)}{\delta u}=(1-\xi) \frac{p(\theta)}{u}$

${ }^{16}$ Note that the congestion effect following from today's job creation affecting today's labour market tightness is reflected by the expected surplus of a match with a new hire being weighted by the elasticity of vacancies in the matching function $(1-\xi)$.
} 
workers' bargaining power satisfies this parameter condition.

Proposition 1. In the presence of skill erosion during unemployment, the decentralized allocation is no longer constrained-efficient under the standard Hosios condition for workers' bargaining power $\eta=\xi$.

Proof. Combining equation (29) with equations (25), (26), (27), and (28) for $l=g=1$, gives the following job creation equation in the decentralized allocation

$$
\frac{\kappa}{q(\theta(x))}=(1-\eta)\left[\bar{y}(x)-b+\beta E_{x}\left\{\Lambda^{D}\left(x^{\prime}\right)\right\}\right]
$$

where $\Lambda^{D}$ represents the continuation value of the match and is given by

$$
\Lambda^{D}(x) \equiv \Lambda_{1}^{D}(x)+\Lambda_{2}^{D}(x)+\Lambda_{3}^{D}(x)
$$

where

$$
\begin{gathered}
\Lambda_{1}^{D}(x) \equiv(1-\gamma)\left(\frac{\kappa}{q(\theta(x))(1-\eta)}+y^{H}(A)-\bar{y}(x)\right) \\
\Lambda_{2}^{D}(x) \equiv-\eta(1-\gamma) p(\theta(x))\left(\frac{\kappa}{q(\theta(x))(1-\eta)}\right) \\
\Lambda_{3}^{D}(x) \equiv \eta p(\theta(x))\left[\gamma\left(y^{H}(A)-\bar{y}(x)\right)+\left(\bar{y}(x)-y^{L}(A)\right)\right]
\end{gathered}
$$

The job creation equation in the constrained-efficient allocation is represented by equation (31). To facilitate comparison with the job creation equation in the decentralized allocation the second and the third part of the continuation value (equation (32)) are expressed below in a slightly different way. ${ }^{17}$

$$
\begin{gathered}
\tilde{\Lambda}_{2}^{P}(x) \equiv-\xi(1-\gamma) p(\theta(x))\left(\frac{\kappa}{q(\theta(x))(1-\xi)}\right) \\
\tilde{\Lambda}_{3}^{P}(x) \equiv p(\theta(x))\left[\gamma\left(y^{H}(A)-\bar{y}(x)\right)+\left(\bar{y}(x)-y^{L}(A)\right)\right]
\end{gathered}
$$

Setting $\eta=\xi$ makes (33) identical to (31), except that $\Lambda_{3}^{D}(x)=\eta \tilde{\Lambda}_{3}^{P}(x)$. It follows that the decentralized allocation does not replicate the constrained-efficient allocation under the standard Hosios condition $\eta=\xi$.

Proposition 1 follows from human capital depreciation during unemployment generating a composition externality in job creation. Because of this externality the

17 This separates those terms which are in terms of hiring costs $\left(\tilde{\Lambda}_{2}^{P}\right)$ and those which are in terms of next period's output gains following from today's job creation affecting the skills of next period's job-seekers $\left(\tilde{\Lambda}_{3}^{P}\right)$. 
output gain from preventing a worker to lose skills, and in case of separation, the output gain from employment allowing a worker to keep her productivity or regain her productivity when she had eroded skills upon hiring, show up only to a fraction of the workers' bargaining power in the decentralized allocation, whereas those output gains show up fully in the planner's allocation. Note that also in the social planner's allocation these output gains only matter to the extent that they are realized, i.e. if the worker whose skills are affected becomes employed which happens with probability $p(\theta)$ as discussed in section 3.1. Given that these output gains, and the probability that they are realized, are state-dependent, so is the magnitude of the composition externality.

How the composition externality arises can be seen from the firm's job creation decision. The latter is obtained by combining equations (13), (14), and (15)

$$
\frac{\kappa}{q(\theta(x))}=\bar{y}(x)-\bar{w}(x)+(1-\gamma) \beta E_{x}\left\{\frac{\kappa}{q\left(\theta\left(x^{\prime}\right)\right)}+B^{H}\left(x^{\prime}\right)\right\}
$$

where $\bar{w}(x) \equiv\left(1-s\left(n_{-1}\right)\right) w^{H}(x)+s\left(n_{-1}\right) w^{L}(x)$ represents the expected wage cost of a new hire, and where $B^{i}(x) \equiv\left(y^{H}(A)-w^{H}(x)\right)-(\bar{y}(x)-\bar{w}(x))$ can be interpreted as the firm's benefit from employing a worker of type $i{ }^{18}$ The above expression shows that vacancy posting is such that the expected hiring cost (LHS) equals the expected output produced by a new hire, taking into account the expected wage cost of a new hire and the continuation value of the match (RHS). The latter shows that firms internalize how today's hiring decisions affect workers' productivity when the worker remains employed. But it also shows that firms ignore their effect on workers' skills if the match with a worker separates or if a worker had never been hired by the firm in the first place. Those effects are still partially accounted for in equilibrium (equation (33)) through the wage setting mechanism. Workers recognize that being in a job affects their skills, and hence their outside option. Therefore, as being discussed in section 2.5, it is reflected in the wage. Note, however, that even though those output effects are only partially internalized,

\footnotetext{
${ }^{18}$ When $\delta=0$ this benefit becomes zero and the value from employing a worker equals the expected hiring cost because a worker of a given type can be replaced by the worker of the same type by paying this cost.
} 
the value of a match with a worker of a specific type in equilibrium is evaluated in the same way as in the planner's allocation for $\eta=\xi .19$

\section{Attaining Constrained-Efficiency}

\subsection{Wage Setting Mechanism}

The decentralized allocation is no longer constrained-efficient under the standard Hosios condition as shown in Proposition 1. But, just as in the absence of skill erosion, this condition internalizes the congestion externality.

Proposition 2. In the presence of skill erosion during unemployment the standard Hosios condition $\eta=\xi$ internalizes the congestion externality when workers have the same hiring probability.

Proof. See Appendix A.2

The same parameter condition internalizes the congestion externality because there is no interaction between the congestion effect and the unemployment pool's composition. When labour market tightness changes, the hiring probability for all workers is affected in exactly the same way because they all have the same hiring probability. Therefore, the effect of job creation on labour market tightness, and hence on the probability that a match starts producing, is independent of the unemployment pool's composition.

Next, I analyze if the standard Hosios condition can be modified such that both the congestion and the composition externality are internalized. Put differently, I examine whether there exists a parameter condition for the workers' bargaining power for which the decentralized allocation is constrained-efficient.

Proposition 3. In the presence of skill erosion during unemployment and aggregate shocks, there is no constant bargaining power $\eta$ such that constrained-efficiency is

\footnotetext{
${ }^{19}$ This is because of the wage setting mechansim: the firm's value of employment is given by $J^{i}(x)=\frac{\kappa}{q(\theta(x))}+B^{i}(x)$, and the wage setting mechanism implies that $B^{i}=(1-\eta)\left(y^{i}(A)-\bar{y}(x)\right)$. Given that $M^{i}(x)=\frac{J^{i}(x)}{(1-\eta)}$, the value of a match with a worker of type $i$ is just as in the social planner's allocation given by the sum of the expected hiring cost and the difference in output generated by this worker and an average worker from the unemployment pool.
} 
attained in all states of the world.

Proof. See Appendix A.3

The intuition behind proposition 3 is the following. The social planner takes into account both the worker's outside option and the congestion effect following from having a job-seeker less if the match does not separate. The former lowers the continuation value because a matched worker cannot be employed elsewhere. The latter increases the continuation value because when a worker stays in the match, it is easier for the other searchers to find a job. What matters is the net effect (given by the sum of the second and third term in expression (32)). But in the decentralized allocation, it is the outside option of the worker up to a fraction of the worker's bargaining power which is taken into account. In the absence of skill loss, this outside option can be expressed as a constant fraction of the net effect. But in the presence of skill erosion the net effect can no longer be expressed as a constant fraction of the worker's outside option (net of the value of home production $b$ ). Consequently, for a constant bargaining power the net effect is not fully taken into account in all states of the world, and hence there is no constant bargaining power for which the decentralized allocation is constrained-efficient in all states of the world.

In contrast, when workers' bargaining power is allowed to be state-dependent, i.e. $\eta(x)$, constrained-efficiency can still be attained without policy intervention. This can be explained as follows. The only decision which has to be made is how many vacancies to post. Therefore, the decentralized allocation is constrained-efficient when the expected gain from job creation is the same as in the planner's allocation, i.e. the RHS of equation (33) and (31) are equalized. The latter depends on both the expected surplus of a new match and the share of this surplus that goes to the firm $(1-\eta(x))$. From this it follows immediately that when the share is allowed to be state-dependent the constrained-efficient allocation can be attained without policy intervention. Because even if the expected surplus of a new match differs across allocations the share that the firm receives can be adjusted such that the expected gain from job creation is the same in both allocations. ${ }^{20}$

\footnotetext{
${ }^{20}$ Note that for the same reason in the steady state there also exists a parameter condition for workers' bargaining power such that constrained-efficiency is attained.
} 


\subsection{Optimal Labour Market Policy}

The previous section's results imply that some form of policy intervention is required to restore constrained-efficiency when worker's bargaining power is constant. This section analyses which labour market policy can replicate the constrainedefficient allocation, which in turn provides insight into the composition externality's magnitude. The policy maker is subject to the same technological constraints and labour market frictions as the planner. I assume throughout that the policy maker can implement a labour market policy through non-distorting revenue sources.

I find that the constrained-efficient allocation can be replicated when implementing the appropriate employment subsidy. ${ }^{21}$ The derivation is described in Appendix A.4. This subsidy is received in every period by firms when they employ a worker independently of the worker's type. Note also that in the presence of an employment subsidy, workers' skills are still only affected by their employment history, leaving the trade-offs related to job creation unaffected.

Since the congestion externality is already well-understood in the literature, I focus on the case where that externality is fully internalized $(\eta=\xi)$. When only the composition externality remains, the optimal employment subsidy $\Phi(x)$ is given by

$$
\begin{aligned}
\Phi(x) & =(1-\xi) \beta E_{x}\left\{p\left(\theta\left(x^{\prime}\right)\right)\left[\left(\bar{y}\left(x^{\prime}\right)-y^{L}\left(A^{\prime}\right)\right)+\gamma\left(y^{H}\left(A^{\prime}\right)-\bar{y}\left(x^{\prime}\right)\right)\right]\right\}>0 \\
& =(1-\xi) \beta E_{x}\left\{p\left(\theta\left(x^{\prime}\right)\right)(1-(1-\gamma) s(n)) \delta A^{\prime}\right\}>0
\end{aligned}
$$

The above expression shows that employment should be subsidized to attain constrainedefficiency. This reflects that not enough jobs are created in the laissez-faire economy in all states of the economy, which follows from the expected social benefits of today's job creation being larger than the private ones.

The optimal subsidy captures the share of the output gains, conditional on being realized, generated by the impact of today's hiring decisions on the unemployment pool's skill composition, which are not internalized in the decentralized allocation. As a result, the optimal subsidy consists of three state-dependent terms: the job finding probability, the fraction of low-skilled workers in the unemployment pool,

\footnotetext{
${ }^{21}$ Note that this does not necessarily imply that there are no other types of instruments that could restore constrained-efficiency.
} 
and aggregate productivity. The job finding probability shows up because the social gain of preventing workers from losing their productivity only matters to the extent that those workers are likely to be hired. The other two terms reflect that the output gain from hiring depends both on the unemployment pool's composition and on the difference in productivity between the worker types. The unemployment pool's composition matters for two reasons. First, the larger the share of job-seekers who already have their skills eroded, the smaller the impact of firms' hiring decisions on the pool's quality. Second, the larger the share of job-seekers with eroded skills, the smaller the social cost of having a low-skilled worker producing because the expected productivity difference between a new hire and a low-skilled worker decreases. The difference in productivity between worker types also shows up, because the social gain of preventing workers from losing skills also depends on this productivity difference. $^{22}$

\section{Labour Market Outcomes}

This section contains two different exercises. Section 5.2 sheds light on how skill loss during unemployment changes labour market outcomes relative to an economy without skill loss. Labour market outcomes are expected to change relative to an economy where the unemployed are not exposed to skill loss because its presence affects the workers' and the firms' problem. But whether on average more or less jobs will be created in the presence of skill loss is not clear because the equilibrium job creation equation (equation (33)) shows that there are two opposing effects at work. On the one hand, the expected gain from job creation drops because the expected output produced by a new hire decreases relative to a world without skill loss. On the other hand, there are additional expected output gains following from today's job creation affecting workers' skills. By looking at how job creation changes relative to an economy without skill loss, it can be understood which of the opposing effects dominates.

\footnotetext{
${ }^{22}$ The latter is a function of aggregate technology because the effect of skill loss is multiplicative. If the effect of skill loss was assumed to be additive the productivity difference would no longer depend on aggregate technology.
} 
I perform this exercise also for the constrained-efficient allocation. Even though it is clear that job creation in the decentralized allocation is lower than in the constrained-efficient allocation when the adequate policy is absent (see section 4), comparing labour market outcomes in both allocations provides an insight into whether the change in job creation in the decentralized allocation induced by skill loss goes in the same direction as the change in job creation in the constrainedefficient allocation.

Section 5.3 seeks to quantify the importance of the composition externality. Therefore, I quantify the extent to which labour market outcomes should change to reach constrained-efficiency by comparing labour market outcomes in the decentralized and the constrained-efficient allocation.

For both exercises I use the model's version where workers lose and regain skills with some probability in every period. For a description of the generalized model for the constrained-efficient allocation, see Appendix A.6. The model is solved numerically by taking a first-order approximation. ${ }^{23}$

\subsection{Calibration}

The parameterization strategy is the following. The length of a period is one month. I use parameter values standard in the literature for the US economy. I set the discount factor $\beta$ to 0.996 implying an annual interest rate of $4 \%$; I set the elasticity of unemployment in the matching function $\xi$ to 0.5 following the evidence in Petrongolo and Pissarides (2001). I set $\eta=\xi=0.5$ such that the congestion externality is

\footnotetext{
${ }^{23}$ Alternatively, the model could be solved through value function iteration. The drawback of this method is the computional time following from the economy's state space being 4-dimensional. One of the advantages of solving this model with a non-linear solution method, however, is the possibility of exploring the importance of non-linearities. The latter are potentially important in an environment with skill loss as the shape of the economy's response to a given shock might depend on its size, which can be explained as follows. The initial response of the job finding probability depends on the size of the shock hitting the economy. As a result, the initial response of the average unemployment duration, and hence the change of the unemployment pool's composition also depends on it. The latter in turn affects the expected gains from job creation in future periods. Consequently, the shape of the economy's response to a shock might depend on the extent to which the shock hitting the economy affects the unemployment pool's composition. I leave the exploration of this channel for future research.
} 
internalized. The value of home production $b$ is set to 0.71 following Hall and Milgrom (2008) and Pissarides (2009). I target the following long-run values, which correspond to the model's steady state values: a job finding probability of $35 \%$ following Fujita and Ramey (2012) and an unemployment rate of 5\% following Blanchard and Gali (2010) where total unemployment is given by all those searchers who did not find a job $\tilde{u} \equiv(1-p(\theta)) u$. This implies an exogenous separation rate of $\gamma=\tilde{u} p(\theta) /((1-\tilde{u})(1-p(\theta)))=0.0283$, which lies in the range of values used in the literature. ${ }^{24} \mathrm{I}$ follow Pissarides (2009) and set $\theta=0.72$, implying a value for matching efficiency $B=p(\theta) \theta^{\xi-1}=0.412$. Steady state aggregate productivity $A$ is normalized to 1 . Once the values of the parameters governing the skill loss process are determined, the value of the vacancy posting $\kappa$ is obtained from the equilibrium conditions.

The parameters governing the skill loss process are $\delta, l$, and $g$. The parameters $\delta$ and $l$ determine the degree to which an unemployment spell erodes workers' skills: the human capital depreciation rate $\delta$ determines how many skills a high-skilled worker loses conditional upon losing, whereas the probability that a high-skilled worker will lose some of its skills in each period that she spends in unemployment depends on $l$. The parameter $g$ determines how long it takes on average for a worker with eroded skills to regain those skills. Importantly, the difference in nature between the exercises performed in section 5.2 and 5.3 requires a different strategy for pinning down $\delta, l$, and $g$.

The exercise in section 5.2 needs a baseline economy which I pick to be the economy without skill erosion. For this economy, I apply the parameterization strategy described above. Therefore, the value of the vacancy posting cost $\kappa$ in the baseline economy is obtained from the vacancy creation condition (equation (33)) when setting $\delta=0$. This gives $\kappa=\frac{(1-\eta) p(\theta)(y-b)}{\theta(1-\beta(1-\gamma)(1-\eta p(\theta)))}=0.3497$.

Next, to analyze how the presence of skill erosion during unemployment affects labour market outcomes relative to the baseline economy, I keep the parameter values $\beta, \xi, \eta, b, \gamma, B$, and $\kappa$ fixed at their value for the baseline economy and vary only those related to the human capital process: $\delta, l$, and $g$. I also keep the steady

\footnotetext{
${ }^{24}$ For example, Fujita and Ramey (2012) target an average monthly separation rate of 0.02, Pissarides (2009) one of 0.036, and Shimer (2005) one of 0.033.
} 
state value for aggregate technology $A$ equal to one. This implies that the steady state values of unemployment $(\tilde{u})$, the job finding probability $(p(\theta))$ and labour market tightness $(\theta)$ will differ from those of the baseline economy. Note that it is precisely this variation that will shed light on how job creation changes when skill loss is present. Finally, given that this exercise is purely qualitative and direct empirical evidence on those three values is absent, I explore the effect of skill loss on labour market outcomes for an entire range of parameter values for $\delta, l$ and $g$. In particular, when I vary one of those parameters over a certain range, I keep the other parameters fixed at an arguably reasonable baseline value, namely $\delta=0.3$, and $l=g=0.167$, which implies that workers both lose and regain skills after six months on average. 25

In section 5.3, in contrast, I parameterize the economy taking into account skill loss during unemployment. Therefore, the main difference relative to the parameterization strategy for section 5.2, is that now the steady state values of the unemployment rate $(\tilde{u}=5 \%)$, the job finding rate $(p(\theta)=0.35)$, and the aggregate labour market tightness $(\theta=0.72)$ are reached when skill loss is present. Thus, the value of the vacancy posting cost $\kappa$ is now computed from the equilibrium conditions of an economy with skill loss. Given that direct empirical evidence on $\delta, l$, and $g$ is absent, I propose a strategy to obtain values for these parameters which makes use of two model predictions.

First, because a fraction of the new hires has eroded skills, the model predicts that a productivity gap arises between an average new hire and an incumbent worker which is interpreted as being high-skilled. Over time this productivity gap closes because those workers with eroded skills regain them. The training literature provides empirical evidence on how long it takes on average for a worker to be fully trained and qualified which I use to pin down $g$. This provides a first insight even though the evidence refers to both the time to acquire firm specific skills and to regain those skills lost because of being unemployed. The estimates for the average time it takes

\footnotetext{
${ }^{25}$ For those parameter values the Blanchard-Kahn (1980) conditions are satisfied which implies that the solution is stable and unique. Pissarides (1992) and Coles and Masters (2000) have shown, in a model without aggregate uncertainty, that multiple equilibria can arise in the presence of skill loss during unemployment. For a discussion about the possibility of multiple equilibria in this model see Appendix A.5.
} 
to become fully trained range from 13.4 weeks (Cairó and Cajner (2011)) to 19.9 months (Barron et al. (1997)), so I set $g=0.083$ such that it takes on average 12 months to regain skills, i.e. $1 / g=12$.

Second, the model predicts wage differences across workers because those with eroded skills earn less than those without eroded skills. Whether a worker has eroded skills depends on the length of their unemployment spell because it is precisely the spell's length which determines the chance that workers lose skills. As a result, the model predicts that on average the length of a worker's past unemployment spell lowers a worker's wage relative to the situation where this worker had not been unemployed in the first place. ${ }^{26}$ The presence of learning-by-doing in turn implies that the effect of an unemployment spell on workers' re-employment wages will faid away over time as those workers with eroded skills regain their skills.

The displacement literature has provided empirical evidence on the negative and long lasting effects of job loss on both earnings and wages. ${ }^{27}$ In line with the predictions of the model, at least part of the wage loss is shown to be caused by the length of the unemployment spell. For example, by using data from the Displaced Worker Survey, Addison and Portugal (1989) find that an increase in the unemployment duration by $10 \%$ reduces wages between $0.8 \%$ and $1.4 \%$. Using the same data, Neal (1995) finds that an additional week of unemployment reduces the wages by $0.37 \%$, implying a monthly rate of wage loss of $1.5 \%$. By using data from the PSID, Ortego-Marti (2012) finds that an additional month of unemployment lowers wages by $1.2 \%$. But to the extent that there is not controlled for unobserved heterogeneity, these estimates are potentially biased by selection effects. In a recent paper, using administrative data from Germany, Schmieder, von Wachter, and Bender (2013) address this problem by proposing an estimation strategy based on using unemployment insurance extensions as an instrumental variable. The range of estimates they

\footnotetext{
${ }^{26}$ In this model the mere fact of displacement does not affect workers' skills. No skills are lost at the moment of becoming unemployed but only during the unemployment experience. Note that it is precisely this type of skill loss that gives rise to the composition externality. This follows from the externality's nature because it only arises when firms affect the unemployment pool's composition in terms of job-seekers' skills. If all the skill loss, and hence wage loss, was driven by skill loss at the moment of displacement then there would be no composition externality. This because job-seekers' skills would be unaffected by their unemployment duration, and hence by firms' hiring decisions.

${ }^{27}$ See e.g. Couch and Placzek (2010), Jacobson et al. (1993), Stevens (1997).
} 
find implies that an increase in the unemployment duration of one month lowers the re-employment wage between $0.7 \%$ and $1.3 \%$, which is in line with the results discussed above. ${ }^{28}$

The empirical evidence on the causal effect of unemployment duration on re-employment wages cannot be used to pin down uniquely the parameters $\delta$ and $l$. The degree to which the length of an unemployment spell lowers workers' re-employment wages is determined both by how long it takes on average before unemployment affects workers' skills $(l)$ and if workers lose skills, how much they lose $(\delta)$. Hence, a given effect can be caused by a range of combinations of the parameters $l$ and $\delta$. Thus, computing a precise value for the extent to which labour market outcomes would change if the composition externality was eliminated is not possible. Nevertheless, it is possible to provide a range of parameter combinations for $\delta$ and $l$ in line with the empirical evidence. This in turn provides a first insight into the quantitative importance of the composition externality.

To obtain a range of parameter combinations for $\delta$ and $l$ in line with the empirical evidence I proceed as follows. First, I pin down the time it takes on average for workers' skills to erode when they are unemployed. Given the lack of empirical evidence, I look at a range of values, namely 3, 6 and 9 months to analyse how the findings depend on the assumed pace of skill loss. ${ }^{29}$ Next, in order to be in line with the empirical evidence I set the value for the human capital depreciation rate $\delta$ such that I match the estimated effect of the length of an unemployment spell on wages. In particular, for a given average pace of skill loss $1 / l$ and an initial guess for $\delta$, I generate artificial employment histories and the according wage paths from the model. ${ }^{30}$ I use those panel data obtained from the model to regress wages on

\footnotetext{
${ }^{28}$ The negative effect of unemployment duration on wages might also operate through other channels such as stigma but they argue that at first sight they do not find evidence in favour of stigma and find suggestive evidence for human capital depreciation.

${ }^{29}$ Given the high turnover in the US labour market, an average pace of skill loss of 3 months implies that an unemployment spell of an average length already leads to skill erosion; given the definition in the US that a long-term unemployed worker is a worker who has been unemployed for at least 26 weeks, 6 months implies that on average the skills of a long-term unemployed worker are eroded; 9 months implies that skill loss is mainly a concern for long-term unemployed workers.

${ }^{30}$ I generate an employment history and wage path for 10.000 worker by using the steady state values for the job finding probability and wages. For each worker I compute 400 periods and discard the first 150 periods to avoid an effect from the initial type and employment status of the worker. In
} 
the length of the unemployment spell

$$
\ln (\text { Wage })=\alpha * \text { Length Spell }+\varepsilon
$$

I update the value of $\delta$ and repeat the same procedure until the regression coefficient equals that of the empirical finding reported by Schmieder, von Wachter, and Bender (2013). I do the analysis both for the upper and lower bound of the range of estimates they provide, i.e. $\hat{\alpha}=-0.013$ and $\hat{\alpha}=-0.007$. In the model workers are homogenous aside from their skill level determined by their unemployment duration. Therefore, an unbiased estimate of the causal effect of unemployment duration on re-employment wages is obtained when estimating expression (38) by OLS.

Finally, the process for aggregate technology is set such as to match the empirical evidence on the volatility and the autocorrelation of quarterly US labour productivity. ${ }^{31}$ This implies a value for the autoregressive parameter for technology $\rho_{a}=0.984$ and a standard deviation of the innovations to technology of $\sigma_{a}=0.005$. Note, however, that another process for aggregate technology could be chosen since the goal of this exercise is not to see how well the model performs in replicating the patterns observed in the data.

\subsection{Comparative Statics}

Figures 1-3 show that relative to an economy without skill erosion, steady state labour market outcomes in the laissez-faire economy change in a way similar to those in the constrained-efficient allocation when skill loss is introduced: the more costly an unemployment spell (i.e. the higher $\delta$, the higher $l$, and the lower $g$ )

the model, those workers who get fired and immediately rehired in the same period are not exposed to skill loss. Therefore, I compute the length of a given unemployment spell as the number of periods where the unemployed worker was exposed to skill loss.

${ }^{31}$ Quarterly data for seasonally-adjusted real output per person in the non-form business sector is obtained from the Bureau of labour Statistics series PRS85006163. I restrict the sample to data in the period 1975-2005 to be in line with the period for the empirical evidence regarding the job finding probability provided by Fujita and Ramey (2012). After taking logs and detrending the data by using an HP-filter with smoothing parameter $10^{5}$ as in Shimer (2005), the values for the standard deviation and the quarterly autocorrelation are 0.017 and 0.882 respectively. 
the shorter the average unemployment duration and the lower the unemployment rate. So the presence of low-skilled job-seekers leads to more job creation, despite the fact that a firm can now be matched with a low-skilled worker. This implies that the value of being matched with a high-skilled worker has to increase to the extent that it more than offsets the negative effect induced by having workers with eroded skills as potential new hires. As shown in the lower panels of figures 13 , when workers face the risk of losing skills during unemployment, their outside option worsens. In particular, high-skilled workers' outside option decreases the more costly an unemployment spell becomes, i.e. the outside option is decreasing in $\delta$ and $l$, and increasing in $g$. This in turn lowers wages, making job creation more attractive for firms. ${ }^{32}$ The composition externality, however, prevents job creation to reach the constrained-efficient level.

Figures 4-6 illustrate that both in the decentralized and the constrained-efficient allocation, the presence of skill erosion does not seem to alter the shape of the economy's dynamic response to a persistent aggregate technology shock much relative to an economy without skill erosion. ${ }^{33}$

\subsection{Quantitative Importance}

Table 1 denotes the average labour market outcomes in the decentralized versus the constrained-efficient allocation for different values of the time for skills to erode on average $(1 / l)$ and the corresponding rate of human capital depreciation $(\boldsymbol{\delta})$ for

\footnotetext{
${ }^{32}$ For this mechanism to be at work it is of course crucial that workers' bargaining power is sufficiently high. The lower workers' bargaining power, the smaller the effect of workers' outside option on wages, and hence the less likely it becomes that the positive effect on job creation induced by lower wages more than offsets the negative effect induced by having low-skilled workers searching for jobs.

${ }^{33}$ Pissarides (1992) has shown that skill loss can be a potential explanation for the observed persistence of unemployment fluctuations. The intuition is that when the economy is hit by a negative shock, the increase in the average unemployment duration leads to a deterioration of the unemployment pool's quality. This in turn makes job creation even less attractive, leading to more persistent unemployment fluctuations. This effect has also been explored by Esteban-Pretel and Faraglia (2010) in a model with both labour market and nominal frictions. They find that even though the presence of skill loss improves the performance of the model in terms of the magnitude of the response of unemployment to a monetary shock, it does not improve the model in terms of explaining the observed persistence in unemployment.
} 


\begin{tabular}{|c||c|c|c|c|}
\hline Time for skills to erode on average in months $(1 / l)$ & & 3 & 6 & 9 \\
\cline { 1 - 5 } Human capital depreciation rate $(\delta)$ & & $0.08(0.14)$ & $0.09(0.17)$ & $0.11(0.20)$ \\
\hline \hline Mean unemployment rate $(\tilde{u})$ in $\%$ & D. & \multicolumn{3}{|c|}{5.00} \\
\cline { 2 - 6 } & P. & $4.46(4.08)$ & $4.65(4.40)$ & $4.73(4.56)$ \\
\hline Mean job finding probability $(p(\theta))$ in $\%$ & D. & \multicolumn{4}{|c|}{35.00} \\
\cline { 2 - 6 } & P. & $37.76(39.96)$ & $36.74(38.09)$ & $36.33(37.21)$ \\
\hline Mean share of low-skilled job-seekers $(s)$ in \% & D. & 44.81 & 28.94 & 21.30 \\
\cline { 2 - 6 } & P. & $41.89(39.65)$ & $27.41(26.28)$ & $20.35(19.74)$ \\
\hline
\end{tabular}

Note: this table shows the mean labour market outcomes for the decentralized allocation (D.) and the social planner's allocation (P.) for different values of the time for skills to erode on average and the associated human capital depreciation rate. The results for the case where an additional month of unemployment lowers the re-employment wage by $0.7 \%$ are denoted without brackets. The results for the case where this effect is $-1.3 \%$ are denoted with brackets. Note that given the calibration strategy, the results in the decentralized allocation do not depend on the value of $\delta$.

Table 1: The importance of the composition externality

the upper $(-1.3 \%)$ and lower $(-0.7 \%)$ bound of the range of estimated values for the effect of unemployment duration on re-employment wages. The implied fraction of skills that workers lose while being unemployed is between $14 \%-20 \%$ and $8 \%-11 \%$ respectively. The findings reported in table 1 suggest that the composition externality is quantitatively important. Restoring constrained-efficiency requires the unemployment rate to decrease between $0.92-0.44$ and $0.5-0.27$ percentage points respectively, with a larger required drop the faster unemployed workers lose their skills on average conditional on the effect of unemployment duration on re-employment wages. This decrease in the unemployment rate would require the average job finding probability of $35 \%$ to increase between $4.96-2.21$, and $2.76-1.33$ percentage points respectively. This in turn implies that the average unemployment duration of around 12 weeks should drop between 11 - 5 days, and 6 - 3 days respectively.

As discussed in section 4.2, constrained-efficiency is attained when the adequate employment subsidy is implemented. Table 2 shows some of the properties of this subsidy. First, to get a better idea about the magnitude of the average optimal employment subsidy, the subsidy is expressed as a fraction of the average output per worker, which is denoted by $\tilde{\Phi}$. The optimal subsidy on average is smaller the less 


\begin{tabular}{|c||c|c|c|c|}
\hline \multicolumn{1}{|c||}{$1 / l$} & & 3 & 6 & 9 \\
\cline { 1 - 4 }$\delta$ & & $0.08(0.14)$ & $0.09(0.17)$ & $0.11(0.20)$ \\
\hline$\tilde{u}$ & mean $(\%)$ & $4.46(4.08)$ & $4.65(4.40)$ & $4.73(4.56)$ \\
\hline \multirow{2}{*}{$s$} & vol. rel to $\tilde{u}$ & $5.36(5.74)$ & $4.13(4.24)$ & $3.28(3.32)$ \\
\hline \multirow{4}{*}{} & $\tilde{\Phi}(\%)$ & $4.60(8.19)$ & $3.05(6.00)$ & $2.41(4.38)$ \\
\cline { 2 - 5 } & vol. rel. to $\tilde{u}$ & $0.96(1.85)$ & $0.38(0.77)$ & $0.21(0.42)$ \\
\cline { 2 - 5 } & corr. with $A$ & $0.99(0.99)$ & $0.99(0.99)$ & $0.99(0.99)$ \\
\cline { 2 - 5 } & corr. with $\tilde{u}$ & $-0.99(-0.99)$ & $-0.98(-0.98)$ & $-0.97(-0.97)$ \\
\cline { 2 - 5 } & corr. with $s$ & $-0.94(-0.94)$ & $-0.90(-0.90)$ & $-0.85(0.85)$ \\
\hline
\end{tabular}

Note: $\tilde{\Phi}$ denotes the average of the subsidy as a fraction of an average worker's output. The first-order approximation of the model has been simulated for 301.000 periods and the first 1.000 observations have been eliminated. The volatilities are defined as the standard deviation of the quarterly average of the monthly data, which has been detrended by using an HP-filter with smoothing parameter $10^{5}$.

Table 2: The optimal employment subsidy

costly unemployment is from a social point of view, which concides with an unemployment spell being less likely to result in skill loss and with fewer skills being lost conditional upon losing (i.e. a lower $l$ and a lower $\delta$ ). Second, the standard deviation of the optimal subsidy relative to unemployment shows that the optimal subsidy becomes relatively less volatile the longer it takes for workers' human capital to erode. This can be explained by longer periods for workers' skills to erode implying lower volatility in the share of low-skilled job-seekers in the unemployment pool as can be seen in table 2. Third, the optimal employment subsidy has a strong positive correlation with aggregate productivity, a strong negative correlation with the unemployment rate, and a strong negative correlation with the fraction of low-skilled searchers in the unemployment pool, which is expected given the subsidy's components. These correlations show that the optimal employment subsidy is procyclical, reflecting that the composition externality matters less in recessions than in booms. ${ }^{34}$

\footnotetext{
${ }^{34}$ Note that this finding does not hinge on the source of economic fluctuations. It is important to point out, however, that when aggregate technology shocks are the driving force behind economic fluctuations, the argument for procyclical employment subsidies is reinforced. This is because, for a given skill composition of the unemployment pool, the expected productivity difference between
} 
The labour market dynamics in the decentralized versus the constrained-efficient allocation are shown in figure 7. The simulated series of the labour market outcomes reveal that the difference between labour market outcomes in both allocations is in the first place driven by differences in the mean.

\section{Discussion}

In this section, I discuss the implications of some important assumptions of the model: the search mechanism and the skill loss process.

\subsection{Role of the Search Mechanism}

To understand which role the assumption of random search in combination with a heterogeneous unemployment pool plays in driving the results, I analyse the extreem case where workers with and without eroded skills search for jobs in segmented markets for the case where $l=g=1$. Firms can choose in which market to post vacancies and search in each market remains random.

Proposition 4. When unemployed workers with and without eroded skills search for jobs in separate markets, with each of those markets characterized by random search, and firms can choose in which market to post vacancies, the decentralized allocation is constrained-efficient as long as the standard Hosios condition holds in each market.

Proof. See Appendix A.8

Proposition 4 follows from the composition externality no longer being present when firms can decide which type of worker shows up for job interviews. In this environment job creation still affects unemployed workers' skills, but it no longer affects how likely it is that job-seekers with or without eroded skills show up for job interviews. Thus, job creation no longer determines the average productivity of

a new hire and a worker with eroded skills is increasing in aggregate technology. Therefore, if economic fluctuations are driven by shocks in aggregate technology, there is another channel, in addition to the unemployment pool's composition, through which the expected productivity difference between a new hire and a job-seeker with eroded skills decreases during recessions. 
job candidates, and hence the output that can be generated by a new match. As a result, with segmented labour markets for workers with and without eroded skills the decentralized allocation is constrained-efficient when the standard Hosios condition holds in each market, i.e. the workers' bargaining power equals the elasticity of job-seekers in the respective labour market.

This finding is related to the literature on training dating back to Becker (1964). Acemoglu (1997) has shown that the investment in general training is too low from a social point of view because a worker's employer is not rewarded for the benefits the worker's future employer will receive from the worker's general training. This is in the same spirit as the composition externality which arises because firms are not rewarded for their hiring decisions preventing the unemployment pool's skill composition from worsening, and hence generating productivity gains for future employers. Moen and Rosén (2004) conjecture that training, as described in Acemoglu (1997), would be constrained-efficient if there were separate markets for trained and untrained workers in which the Hosios condition holds. In the same spirit, they argue that their paper's finding, namely that labour market outcomes in a competitive search model with endogenous turnover and endogenous human capital formation are constrained-efficient when firms and workers are able to coordinate efficiently, would no longer hold if workers with different degrees of training were searching in the same submarket. This is in line with this paper's findings.

Proposition 4 implies that the relevance of the composition externality hinges on the extent to which the expected productivity of a new hire depends on the unemployment pool's composition. This in turn depends on the extent to which firms select their pool of job applicants. A recent paper by Kroft et al. (2013) shows that call back rates for job applicants who only differ in terms of the length of their unemployment spell, decrease with the unemployment spell's length. The authors argue that their evidence for true duration dependence shows that firms select, at least to some extent, based on unemployment duration. ${ }^{35}$

\footnotetext{
${ }^{35}$ Note that the presence of true duration dependence does not necessarily require selectivity in the search environment. It also arises in a random search environment once match specific productivity is introduced. When match output is not only a function of aggregate productivity and the worker's skills but also depends on match specific productivity, in the spirit of Mortensen and Pissarides (1994), some matches will separate for endogenous reasons. In particular, only those
} 
Despite the empirical evidence in favour of some degree of selection, I believe that the random search framework is an interesting benchmark. This is because I expect that the key insight from the random search environment, namely the existence of a composition externality with a state-dependent magnitude, will carry over to other search environments as long as there is no perfect selection when the unemployment pool is heterogeneous. In other words, as long as the search environment is such that the expected productivity of a new hire depends on the unemployment pool's composition. But given the finding that there is no composition externality when workers with different skills search in different markets, and hence firms can perfectly select job applicants, I expect the externality's magnitude to be decreasing in the degree of selectivity. I also expect the finding that the composition externality matters less in recessions than in booms to carry over to other search environments. In particular, I expect this to happen when the environment is such that a larger share of workers with eroded skills in the unemployment pool increases the probability of hiring a worker with eroded skills, and hence decreases the expected productivity difference between a new hire and a job-seeker with eroded skills.

\subsection{Skill Loss Process}

This paper's findings suggest that understanding the social cost of letting a worker being unemployed and potentially exposed to skill erosion hinges, among other things, on the human capital depreciation process. This paper has focused on the

matches whose productivity is above an endogenously determined threshold value will start producing. As a result, some job interviews will not result in hiring and some of the existing matches will separate. In this framework workers with a higher unemployment duration have on average a lower hiring probability. Given that low-skilled job-seekers are less productive, match specific productivity has to be higher for those workers than for high-skilled workers for matches to have a non-negative value. Therefore, the threshold value for match specific productivity of low-skilled job-seekers is higher than that of high-skilled job-seekers. This in turn lowers the hiring probability of the low-skilled job-seekers, generating true duration dependence in an environment where the composition externality is present. Given that some matches separate for endogenous reasons, the skill composition of the unemployment pool is affected through two channels instead of one: the vacancy posting decision and the decision on whether a match will start operating. Vacancy creation determines how many job-seekers will get a job interview. But it is the threshold value for match specific productivity which ultimately determines whether workers will be unemployed and exposed to skill erosion. 
case where the process of skill loss is such that skill loss is bounded from below and workers' expected skills are decreasing and convex in their unemployment duration. This process matters for the social cost of letting a worker being unemployed, and hence for the magnitude of the composition externality. First, it implies that human capital depreciation during unemployment not only affects long-term but also shortterm unemployed workers. So also in periods with low average unemployment duration there is scope for increasing hiring to prevent skill erosion. Second, it implies that in booms unemployed workers are at a relatively steep expected skill profile while in recessions they are at a relatively flat expected skill profile, where the steepness depends on how fast unemployed workers lose skills on average. This matters because it determines at which point in the cycle the impact of firms' hiring decisions on the unemployment pool's quality starts reducing. Put differently, it determines at which point in the cycle the share of unemployed workers that can be prevented from losing skills through hiring starts decreasing.

Which skill loss process should be assumed is ultimately an empirical matter. Gregory and Jukes (2001) find that even for short unemployment spells, the length of the spell has a negative effect on the re-employment wage over and above the negative effect of the occurrence of the unemployment spell. ${ }^{36}$ This suggests that, in line with the skill loss process assumed in this paper, not only long-term but also shortterm unemployed workers are affected by human capital depreciation. Moreover, by including a quadratic term for unemployment duration in their estimation, they find that a longer spell brings greater wage loss, but at a diminishing rate. This indicates that, in line with the skill loss process assumed in this paper, loss of human capital is not accelerating with the duration of unemployment. I leave a deeper understanding of the skill loss process and its implications for the social cost of unemployment for future research.

\footnotetext{
${ }^{36}$ They find that an unemployment spell of 30 days reduces earnings by a further $0.8 \%$, rising to $5.1 \%$ for a six-month spell, and to $11.1 \%$ for a one-year spell. Note that they address the potential problem of unobserved heterogeneity by using a Heckmann correction term.
} 


\section{Conclusion}

This paper shows that the depreciation of human capital during unemployment calls for policy intervention when both workers with and without eroded skills search for jobs in the same labour market. This is the consequence of a composition externality related to job creation: when making their hiring decisions, firms do not take into account how their decisions affect the skill composition of the unemployment pool, and hence the expected productivity of other firms' new hires. Hiring affects this composition because it prevents having additional workers with eroded skills in the unemployment pool. Calibrating the model to the US economy reveals that this composition externality is quantitatively relevant. Restoring constrained-efficiency entails a drop in the average unemployment rate in the range of 0.92 to 0.27 percentage points.

More insight into the composition externality is provided by analysing the policy instrument that can replicate the planner's solution when this externality is the only source of inefficiency besides the search frictions characterizing the labour market. The instrument takes the form of an employment subsidy implying that because of this externality job creation in the laissez-faire economy is too low in all states of the economy from a social point of view. But this subsidy is state-dependent revealing that the welfare implications of this composition externality vary over the cycle. This follows from this externality's magnitude depending on the impact of today's job creation on the unemployment pool's skill composition in the next period. Given that this impact varies over the cycle, so does the composition externality's magnitude. In particular, this impact decreases the larger the share of unemployed workers who have already gotten their skills eroded.

How this externality's importance varies over the cycle depends on the point in the cycle at which the share of unemployed workers that can be prevented from losing skills through hiring starts decreasing. This in turn ultimately depends on the skill loss profile, an issue on which empirical evidence is scarce. Therefore, this paper's findings suggest that an important step for further improving our understanding about the social cost of human capital depreciation during unemployment is to provide more evidence about the skill loss process. 
Finally, this paper has focused on the case where the depreciation of human capital during unemployment is the only source of inefficiency besides the search frictions characterizing the labour market. I believe that this environment is appropriate for understanding the nature of the efficiency loss generated by skill erosion. However, I also believe that introducing skill erosion into a richer environment is important because its presence might alter the efficiency loss generated by other frictions in the economy. One example is wage rigidity. This paper has emphasized that firms are still willing to hire the unemployed with eroded skills because those workers' wages are adjusted to bring them in line with their productivity. Therefore, I expect the efficiency loss on average generated by rigid wages to be larger once it is taken into account that the unemployed are exposed to skill erosion because firms might no longer be willing to hire unemployed workers with eroded skills. I leave the exploration of this avenue for future research. 


\section{References}

Acemoglu, Daron. 1997, "Training and Innovation in an Imperfect Labour Market." The Review of Economic Studies, 64 (3): 445-464.

Addison, John, and Pedro Portugal. 1989. "Job Displacement, Relative Wage Changes, and Duration of Unemployment." Journal of Labor Economics, 7(3): 281-302.

Albrecht, James, Lucas Navarro, and Susan Vroman. 2010. "Efficiency in a search and matching model with endogenous participation." Economics Letters, 106(1): 48-50.

Barron, John M., Mark C. Berger, and Dan A. Black. 1997. "How Well Do We Measure Training?" Journal of Labor Economics, 15(3): 507-528.

Blanchard, Olivier, and Jordi Galí. 2010. "Labor Markets and Monetary Policy: A New Keynesian Model with Unemployment.” American Economic Journal: Macroeconomics, 2(2): 1-30.

Blanchard, Olivier, and Charles M. Kahn. 1980. "The Solution of Linear Difference Models under Rational Expectations.” Econometrica, 48(5):1305-1312.

Becker, Gary S. 1964. "Human Capital.” Chicago, University of Chicago Press.

Burdett, Kenneth, and Melvyn G. Coles. 1997. "Marriage and Class.” Quarterly Journal of Economics, 112(1): 141-168.

Burdett, Kenneth, and Melvyn G. Coles. 1999. "Long-term partnership formation: marriage and employment.” Economic Journal, 109(456): 307-334.

Cairó, Isabel and Tomaz Cajner. 2011. "Human capital and unemployment dynamics: why more educated workers enjoy greater employment stability." Working Paper.

Coles, Melvyn G., and Adrian Masters. 2000. "Retraining and long-term unemployment in a model of unlearning by not doing." European Economic Review, 44(9): 1801-1822.

Couch, Kenneth A. and Dana W. Placzek. 2010. "Earnings Losses of Displaced Workers Revisited." American Economic Review, 100(1): 572-589.

den Haan, Wouter J., Christian Haefke, and Garey Ramey. 2005.“Turbulence and Unemployment in a Job Matching Model." Journal of the European Economic Association, 3(6):1360-85.

Edin, Per-Andres, and Magnus Gustavsson. 2008. "Time Out of Work and Skill Depreciation.” Industrial Labor Relations Review, 61(2): 163-180. 
Esteban-Pretel, Julen, and Elisa Faraglia. 2010. "Monetary Shocks in a Model with Skill Loss.” Journal of Money, Credit and Banking, 42(7):1235-1265.

Fujita, Shigeru and Garey Ramey. 2012. "Exogenous versus Endogenous Separation." American Economic Journal: Macroeconomics, 4(4): 68-93.

Gregory, Mary, and Robert Jukes. 2001. "Unemployment and Subsequent Earnings: Estimating Scarring Among British Men 1984-94.” Economic Journal, 111(474): 607-625.

Hall, Robert E., and Paul R. Milgrom. 2008. "The Limited Influence of Unemployment on the Wage Bargain." American Economic Review, 98(4): 1653-1674.

Hosios, Arthur J. 1990. "On the Efficiency of Matching and Related Models of Search and Unemployment." Review of Economic Studies, 57(2): 279-298.

Jacobson, Louis S., Robert J. Lalonde, and Daniel G. Sullivan.1993. "Earning Losses of Displaced Worksers.” American Economic Review, 83(4): 695-709.

Kroft, Kory, Fabian Lange, and Matthew J. Notowidigdo. 2013. "Duration Dependence and Labor Market Conditions: Evidence from a Field Experiment," The Quarterly Journal of Economics,128 (3): 1123-1167.

Keane, Michael P., and Kenneth I. Wolpin. 1997. "The Career Decisions of Young Men.” Journal of Political Economy, 105(3): 473-522.

Laureys, Lien. 2014. "Optimal Monetary Policy in the Presence of Human Capital Depreciation during Unemployment”. CFM Discussion Paper Series, No. CFMDP2014-15.

Ljungqvist, Lars, and Thomas J. Sargent. 1998. “The European Unemployment Dilemma." Journal of Political Economy, 106(3): 514-550.

Ljungqvist, Lars, and Thomas J. Sargent. 2004. "European Unemployment and Turbulence Revisited in a Matching Model." Journal of the European Economic Association, 2(2-3) :456-68.

Ljungqvist, Lars, and Thomas J. Sargent. 2007. "Understanding European unemployment with matching and search-island models." Journal of Monetary Economics, 54(8): 2139 - 2179.

Ljungqvist, Lars, and Thomas J. Sargent. 2008. “Two Questions about European Unemployment." Econometrica, 76(1):1-29.

Moen, Espen R. , and Åsa Rosén. 2004. "Does Poaching Distort Training?” The Review of Economic Studies, 71(4): 1143-1162.

Mortensen, Dale. T., and Christopher A. Pissarides. 1994. "Job Creation and Job Destruction in the Theory of Unemployment." Review of Economic Studies, 61(3): 397-415. 
Mortensen, Dale. T., and Christopher A. Pissarides. 2002. "Taxes, Subsidies and Equilibrium Labor Market Outcomes.” CEP Discussion Papers 0519, Centre for Economic Performance, LSE.

Neal, Derek. 1995. "Industry-Specific Human Capital: Evidence from Displaced Workers.” Journal of Labor Economics, 13(4): 653-677.

Ortego-Marti, Victor. 2012. "Unemployment History and Frictional Wage Dispersion." Working Paper.

Pavoni, Nicola, and Gianluca Violante. 2007. "Optimal Welfare-to-Work Programs.” Review of Economic Studies, 74(1): 283-318.

Pavoni, Nicola. 2009. "Optimal Unemployment Insurance, with Human Capital Depreciation, and Duration Dependence.” International Economic Review, 50 (2): 323-362.

Petrongolo, Barbara, and Christopher A. Pissarides. 2001. "Looking into the Black Box: A Survey of the Matching Function.” Journal of Economic Literature, 39(2): 390-431.

Pissarides, Christopher A. 1992. "Loss of Skill During Unemployment and the Persistence of Employment Shocks." Quarterly Journal of Economics, 107(4):13711391.

Pissarides, Christopher A. 2009. “The Unemployment Volatility Puzzle: is Wage Stickiness the Answer?" Econometrica, 77(5): 1339-1369.

Schmieder, Johannes F., Till von Wachter, and Stefan Bender. 2013. "The Causal Effect of Unemployment Duration on Wages: Evidence from Unemployment Insurance Extensions." Working Paper.

Shimer, Robert, and Lones Smith. 2001. "Matching, Search and Heterogeneity." Advances in Macroeconomics, 1 (1): 1-16.

Shimer, Robert. 2005. "The Cyclical Behavior of Equilibrium Unemployment and Vacancies." American Economic Review, 95(1): 25-49.

Shimer, Robert and Ivan Werning. 2006. "On the Optimal Timing of Benefits with Heterogeneous Workers and Human Capital Depreciation." NBER working paper no. 12230, May.

Spinnewijn, Johannes. 2010. “Training and Search During Unemployment.” Working Paper.

Stevens, Ann Huff. 1997. "Persistent Effects of Job Displacement: The importance of Multiple Job Losses.” Journal of Labor Economics, 15(1): 165-188. 


\section{Figures}

Figure 1: Role of human capital depreciation rate in shaping labour market outcomes
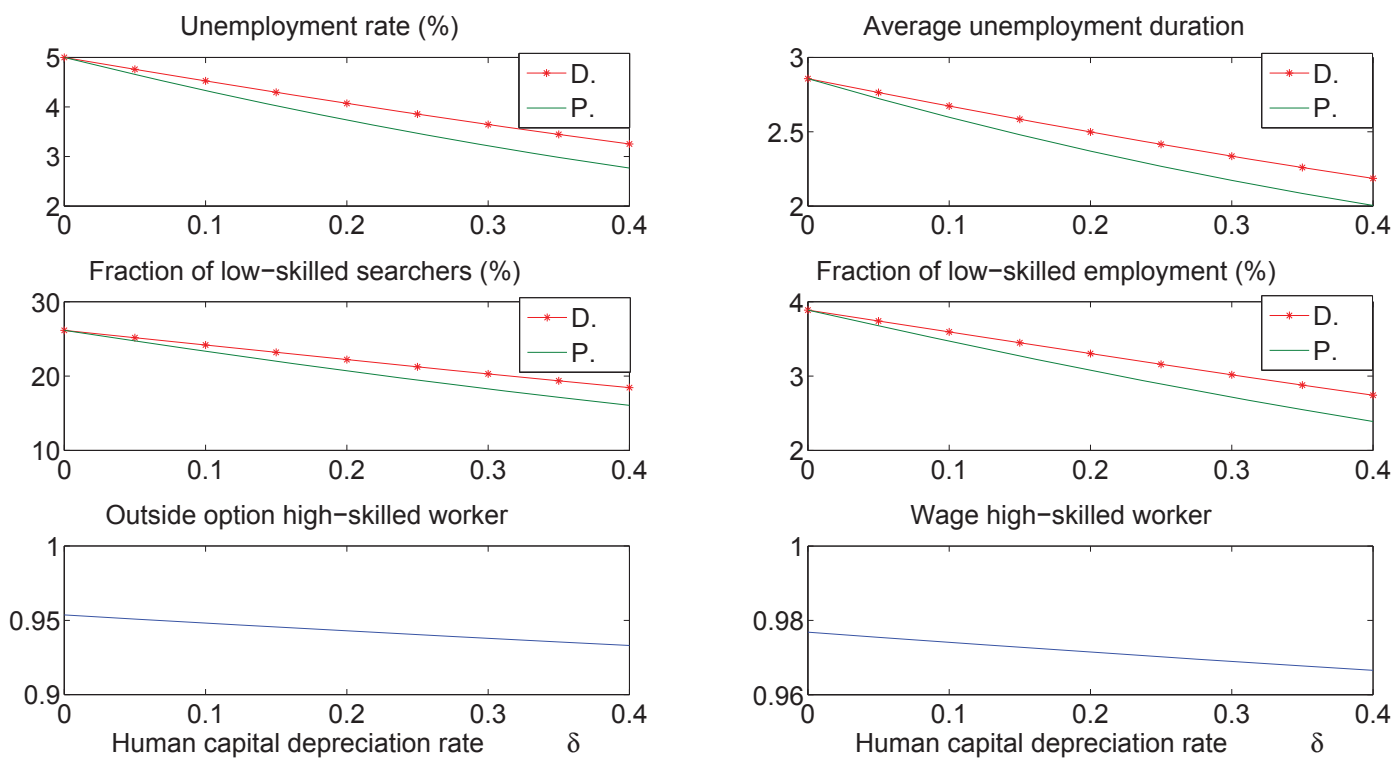

Note: this figure shows the steady state labour market outcomes for different values of the human capital depreciation $\operatorname{rate}(\delta)$ both for the decentralized allocation (D.) and the social planner's allocation (P.). The world without human capital depreciation is attained for $\delta=0$. 


\section{Figure 2: Role of probability of skill loss in shaping labour market outcomes}
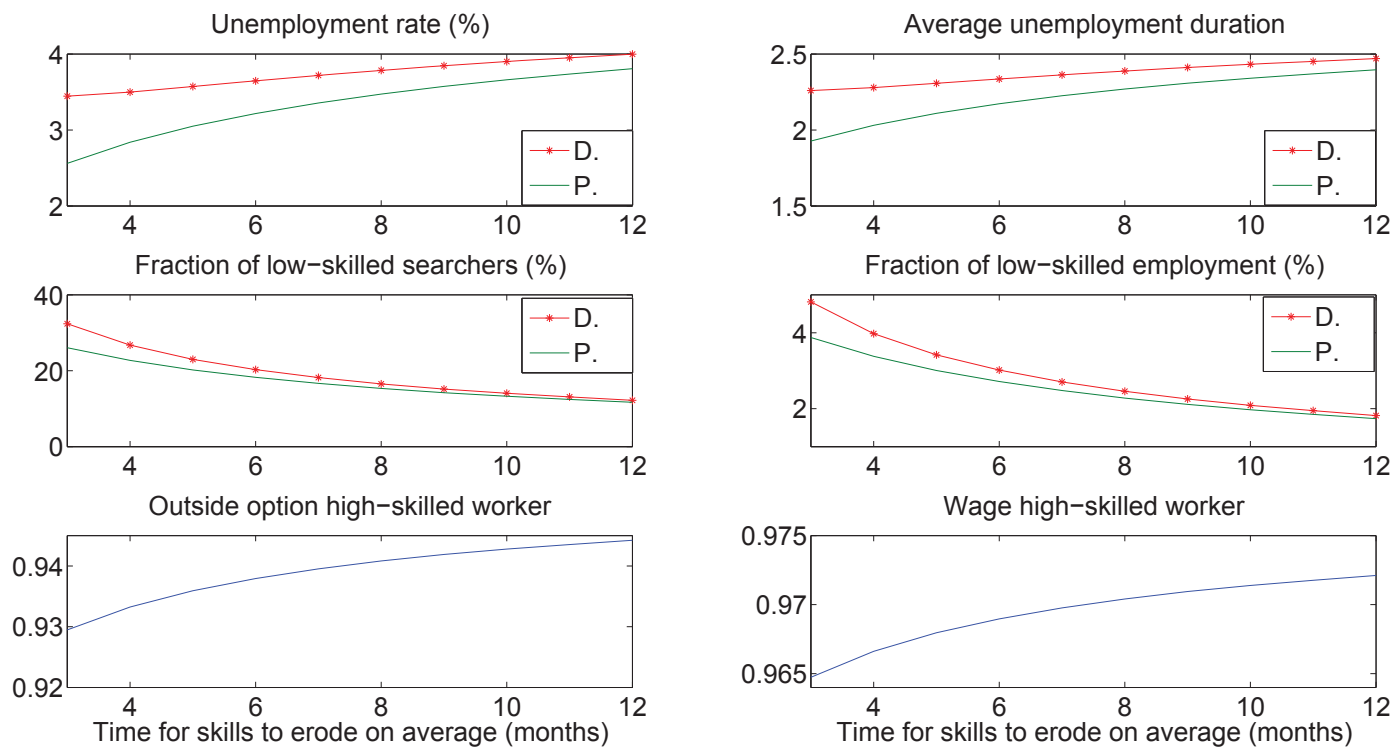

Note: : this figure shows the steady state labour market outcomes for different values of the time it takes for skills to erode on average $(1 / l)$ both for the decentralized allocation (D.) and the social planner's allocation (P.). The world without human capital depreciation would be attained in the limiting case where the time it takes on average for workers to lose skills goes to infinity. 
Figure 3: Role of probability of regaining skills in shaping labour market outcomes
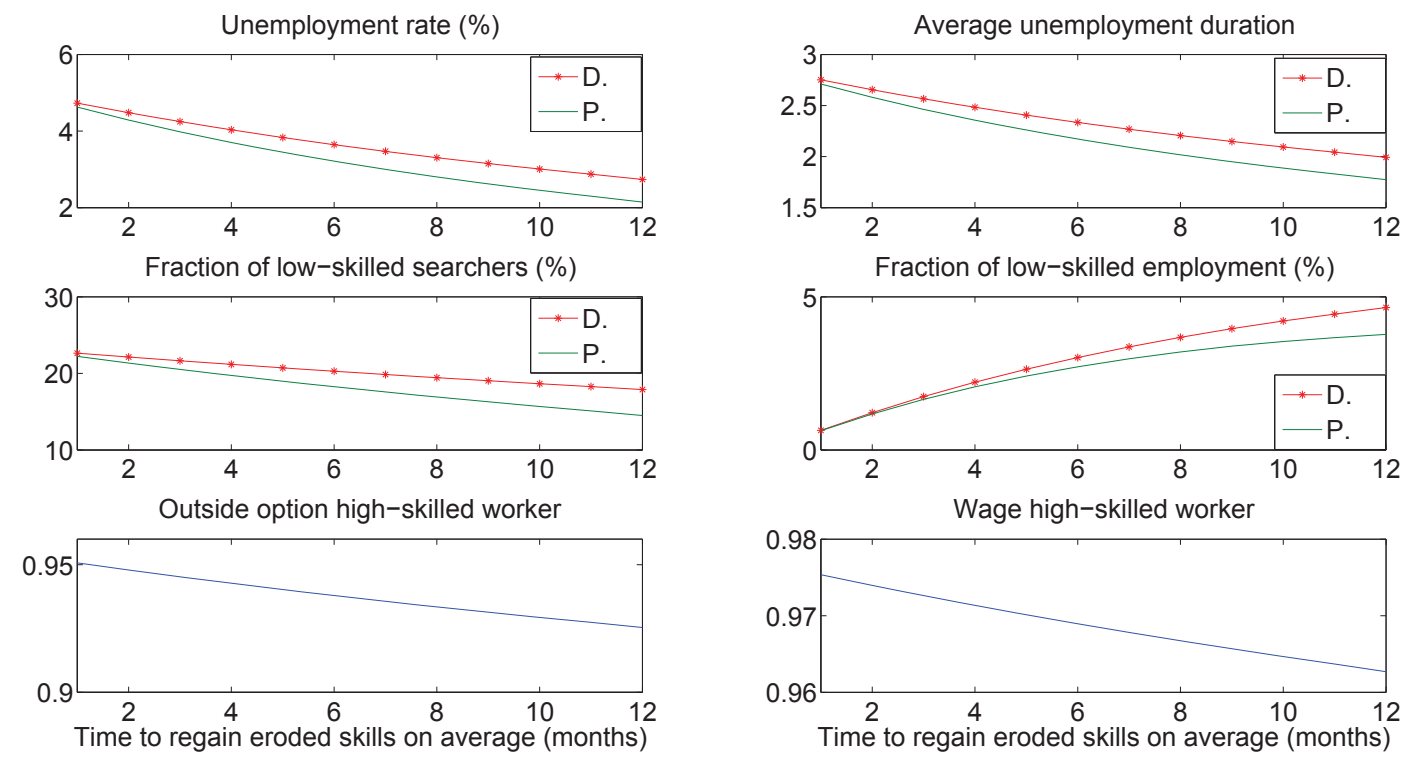

Note: this figure shows the steady state labour market outcomes for different values of the time it takes to regain eroded skills on average $(1 / g)$ both for the decentralized allocation (D.) and the social planner's allocation (P.). The world without human capital depreciation would be attained in the limiting case where workers regain their skills immediately upon hiring before production starts. 
Figure 4: Role of human capital depreciation rate in shaping labour market dynamics
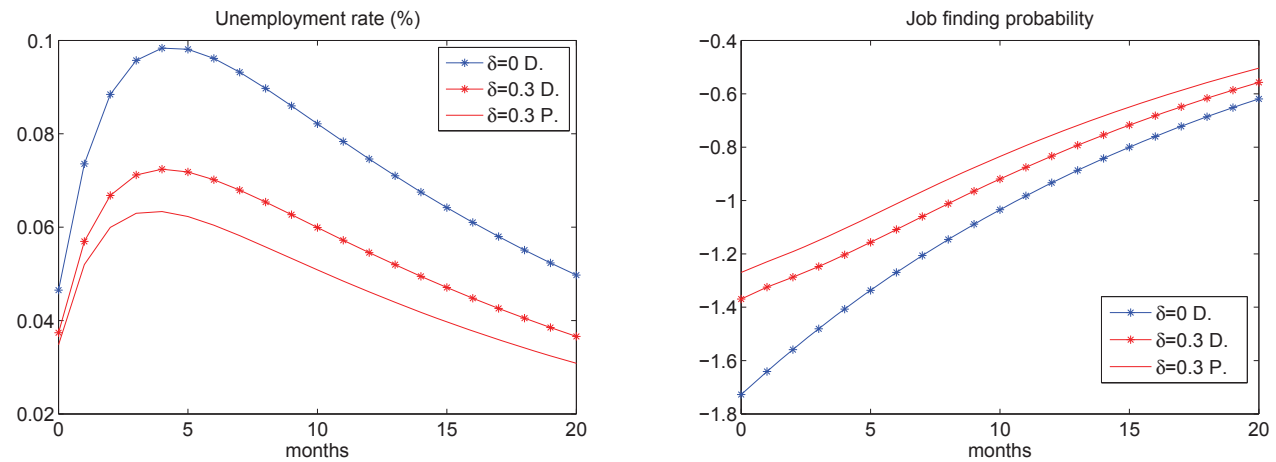

Note: this figure shows the impulse response functions both for the decentralized allocation (D.) and the social planner's allocation (P.) to a persistent negative aggregate technology shock which decreases aggregate technology by $1 \%$ on impact relative to its steady state level and the autoregressive parameter $\rho_{a}=0.95$. The unemployment rate is expressed in terms of absolute deviations from steady state, while the job finding probability is expressed in terms of relative deviations from steady state. Note that the steady states differ for both calibrations shown.

Figure 5: Role of probability of skill loss in shaping labour market dynamics
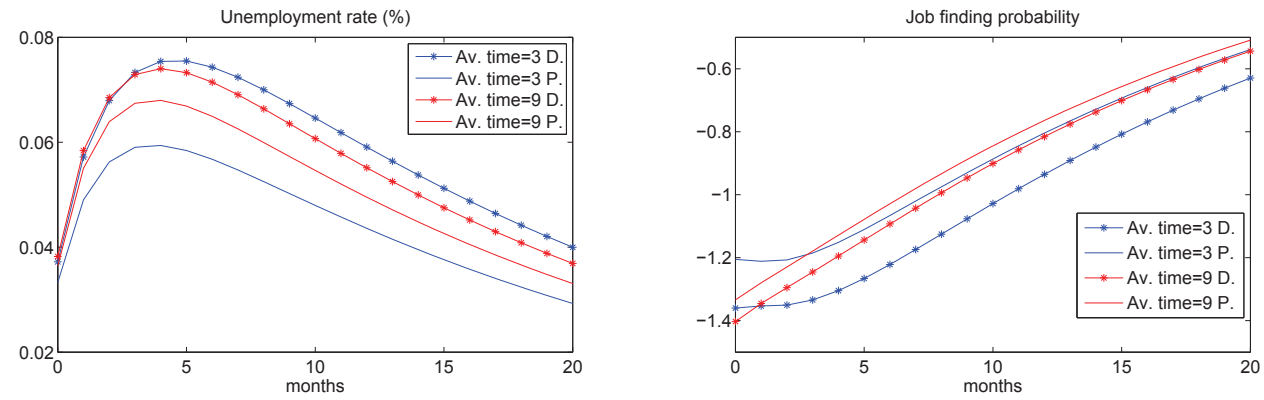

Note: this figure shows the impulse response functions both for the decentralized allocation (D.) and the social planner's allocation (P.) to a persistent negative aggregate technology shock which decreases aggregate technology by $1 \%$ on impact relative to its steady state level and the autoregressive parameter $\rho_{a}=0.95$. The unemployment rate is expressed in terms of absolute deviations from steady state, while the job finding probability is expressed in terms of relative deviations from steady state. Note that the steady states differ for both calibrations shown. 
Figure 6: Role of probability of regaining skills in shaping labour market dynamics
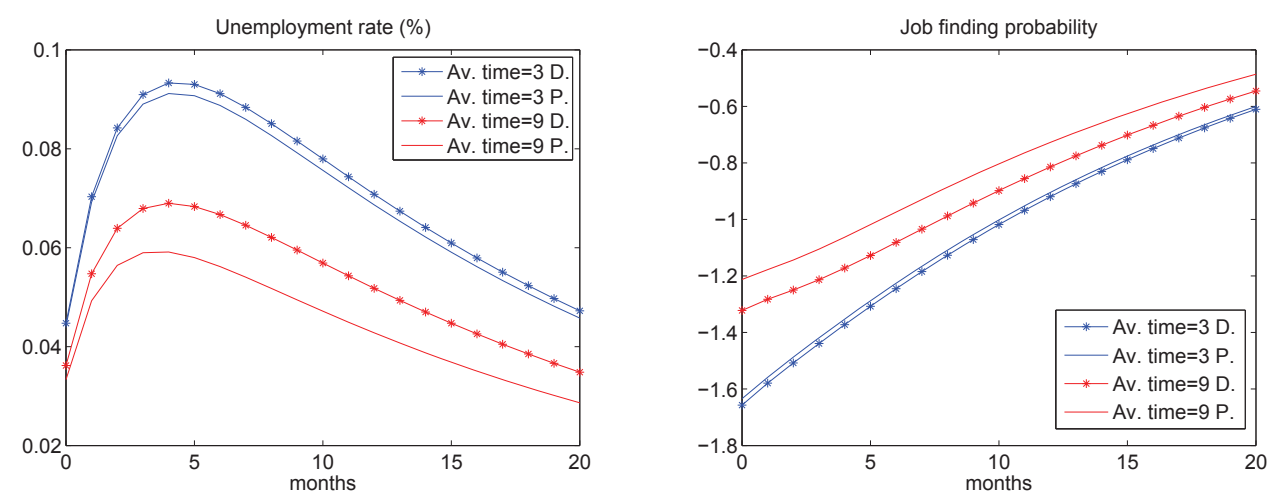

Note: this figure shows the impulse response functions both for the decentralized allocation (D.) and the social planner's allocation (P.) to a persistent negative aggregate technology shock which decreases aggregate technology by $1 \%$ on impact relative to its steady state level and the autoregressive parameter $\rho_{a}=0.95$. The unemployment rate is expressed in terms of absolute deviations from steady state, while the job finding probability is expressed in terms of relative deviations from steady state. Note that the steady states differ for both calibrations shown. 
Figure 7: Labour market dynamics in the decentralized versus the planner's allocation
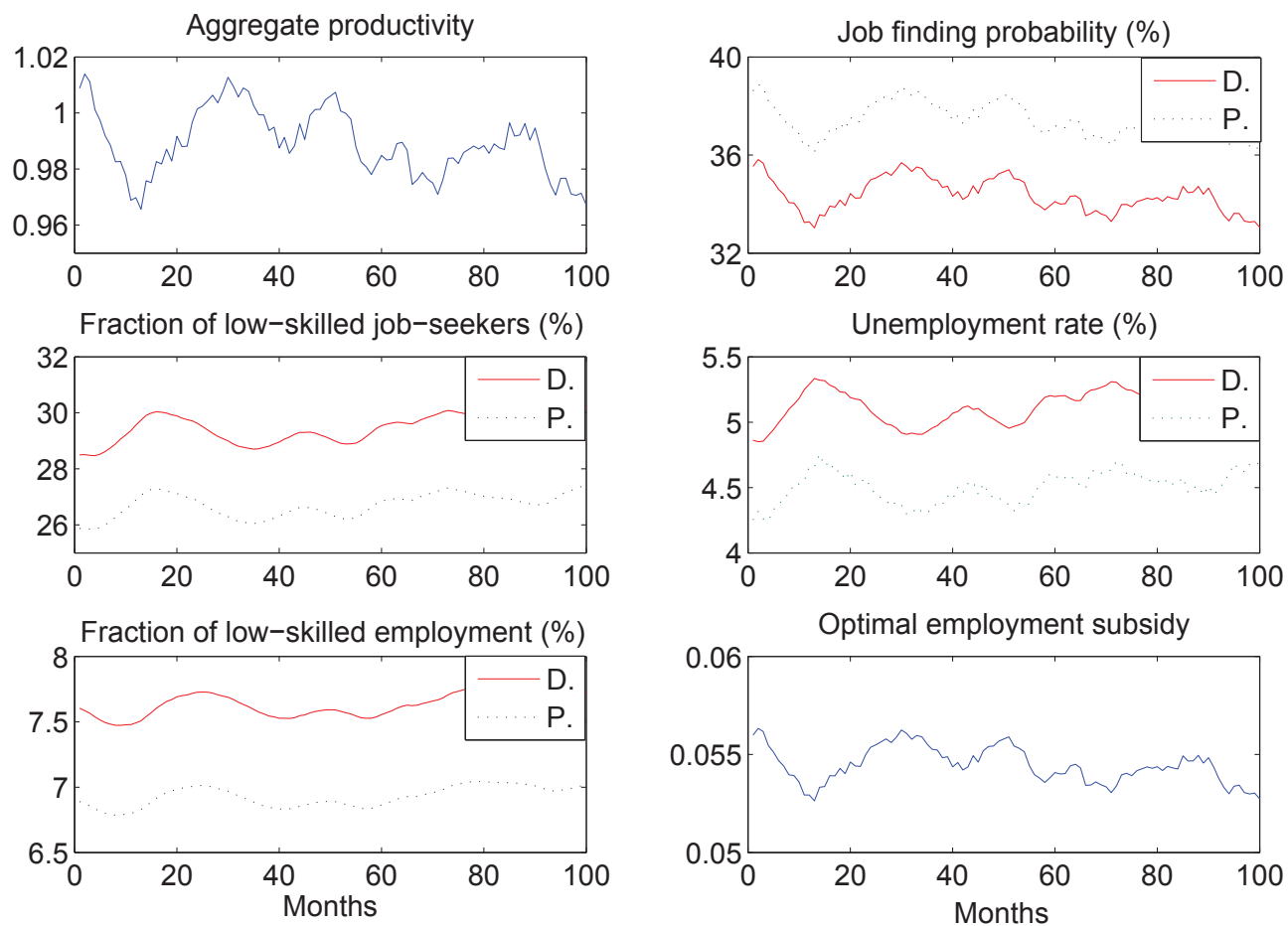

Note: this figure shows simulated series for the labour market outcomes for $\delta=0.17$ and $1 / l=6$ both for the decentralized allocation (D.) and the social planner's allocation (P.). 


\section{A Appendix}

\section{A.1 Social Planner's Allocation}

The first order condition for vacancy creation is

$$
\frac{\kappa}{q(\theta(x))}=(1-\xi)\left[\bar{y}(x)-b+\beta E_{x}\left\{\frac{\partial V^{P}\left(x^{\prime}\right)}{\partial n}\right\}\right]
$$

The envelope condition for employment is

$$
\frac{\partial V^{P}(x)}{\partial n_{-1}}=\left[\begin{array}{c}
(1-\gamma+\gamma p(\theta(x))) y^{H}(A)-p(\theta(x)) y^{L}(A)+(1-\gamma) \kappa \theta(x) \\
-(1-\gamma)(1-p(\theta(x)))\left[b-\beta E_{x}\left\{\frac{\partial V^{P}\left(x^{\prime}\right)}{\partial n}\right\}\right]
\end{array}\right]
$$

Combining the first order condition and the envelope condition for employment gives the vacancy creation equation (equation (31)).

\section{A.2 Proof of Proposition 2}

Proof. By comparing equation (33) and equation (31), it follows that the total effect of this period's vacancy posting on the number of matches that can be formed this period is taken into account when $\eta=\xi$. When the latter is satisfied, the expected surplus of a new match in the decentralized allocation is weighted by the elasticity of vacancies in the matching function $1-\xi$, just as in the social planner's allocation. The effect on next period's labour market tightness following from having a job-seeker less when this period's match survives separation is also internalized for $\eta=\xi$. This can be shown as follows.

For $\delta=0$, this part of the congestion effect is internalized in the decentralized allocation because the net effect of having a job-seeker less when this period's match survives separation, which is generated by the congestion effect and a worker's outside option, can be expressed as a fraction of the worker's outside option. From the constrained-efficient allocation it follows that this net effect, denoted by $\Upsilon$, is given by (see expression (35))

$$
\Upsilon(x) \equiv \tilde{\mathscr{O}}(x)+\Omega(x)=-\frac{\xi}{1-\xi}(1-\gamma) \kappa E_{x}\left\{\theta\left(x^{\prime}\right)\right\}
$$

where the worker's outside option net of home production $\tilde{\mathscr{O}}$ is given by (see the second term of expression (32))

$$
\tilde{\mathscr{O}}(x) \equiv-\left(\frac{1-\gamma}{1-\xi}\right) \kappa E_{x}\left\{\theta\left(x^{\prime}\right)\right\}
$$


and where the congestion effect $\Omega$ is given by (see the third term of expression (32))

$$
\Omega(x) \equiv(1-\gamma) \kappa E_{x}\left\{\theta\left(x^{\prime}\right)\right\}
$$

Comparing equation (39) and the decentralized allocation (equation (33)) shows immediately that for $\eta=\xi$ the congestion effect is internalized, even though only the worker's outside option is taken into account. This follows from the net effect being a fraction $\xi$ of the worker's outside option (net of the value of home production) (equation (40)), and the latter being taken into account up to a fraction $\eta$ in the decentralized allocation.

For $\delta>0$, the net effect is now given by (see expression (35) and (36))

$$
\Upsilon(x)=-\frac{\xi}{1-\xi}(1-\gamma) \kappa E_{x}\left\{\theta\left(x^{\prime}\right)\right\}+E_{x}\left\{\delta A^{\prime} p\left(\theta\left(x^{\prime}\right)\right)[1-(1-\gamma) s(n)]\right\}
$$

where the outside option net of home production is now given by (see the second term of expression (32))

$$
\tilde{\mathscr{O}}(x)=-\left(\frac{1-\gamma}{1-\xi}\right) \kappa E_{x}\left\{\theta\left(x^{\prime}\right)\right\}+E_{x}\left\{\delta A^{\prime} p\left(\theta\left(x^{\prime}\right)\right)[1-(1-\gamma) s(n)]\right\}
$$

and where the congestion effect is still given by equation (41). The congestion effect is still expressed as a function of the match with an average job-seeker because they all have the same hiring probability, and hence a change in labour market tightness affects all job-seekers' hiring probability in the same way.

Comparing equation (42) and the decentralized allocation (equation (33)) shows that the standard Hosios condition $\eta=\xi$ still internalizes the congestion effect even though only the worker's outside option is taken into account. This follows from the fact that this part of the net effect containing the congestion effect (given by the first term in equation (42)) can still be expressed as a fraction $\xi$ of part of the worker's outside option (given by the first term in equation (43)). This in turn follows from both part of the net effect and part of the worker's outside option being able to be expressed as a function of the hiring probability and match value of an average job-seeker.

\section{A.3 Proof of Proposition 3}

Proof. If there exists a constant bargaining power parameter $\eta$ for which the decentralized allocation replicates the social planner's allocation in all states of the economy, then this implies that the RHS of equation (31) and (33) are equalized in all states of the world for this constant parameter. This would imply that there exists a value for $\eta$ such that expression (44) holds in all states of the world

$$
d(x) \eta^{2}+[e(x)-d(x)] \eta+(1-\xi) d(x)-\xi e(x)=0
$$


where $d(x) \equiv \beta E_{x}\left\{p\left(\theta\left(x^{\prime}\right)\right)\left[\gamma\left(y^{H}\left(A^{\prime}\right)-\bar{y}\left(x^{\prime}\right)\right)+\left(\bar{y}\left(x^{\prime}\right)-y^{L}\left(A^{\prime}\right)\right)\right]\right\}$

and where $e(x) \equiv \bar{y}(x)-b+(1-\gamma) \beta E_{x}\left\{\kappa \theta\left(x^{\prime}\right)+y^{H}\left(A^{\prime}\right)-\bar{y}\left(x^{\prime}\right)\right\}$.

It follows immediately that for $\delta \in(0,1)$ the bargaining power $\eta$ which satisfies expression (44) is a function of the economy's state $x$. This implies that there is no constant bargaining power $\eta$ for which expression(44) holds in all states of the economy.

Note that in the absence of human capital depreciation during unemployment, i.e. for $\delta=0$, expression (44) becomes $\left[\bar{y}(x)-b+(1-\gamma) \beta E_{x}\left\{\kappa \theta\left(x^{\prime}\right)\right\}\right](\eta-\xi)=0$. For this expression to hold in all states of the economy, $\eta$ should equal $\xi$, which is the standard Hosios (1990) condition.

\section{A.4 Optimal Labour Market Policy}

\section{A.4.1 The Economy for $l=g=1$}

Changes relative to the setup without an employment subsidy/tax

In the presence of an employment subsidy/tax only the firm's problem is affected. When employment is subsidized/taxed $\Phi(x)$, a firm's value of employing a worker of type $i$ is given by

$$
J_{s}^{i}(x)=y^{i}(A)-w^{i}(x)+\Phi(x)+(1-\gamma) \beta E_{x}\left\{J_{s}^{H}\left(x^{\prime}\right)\right\}
$$

Equation (45) shows that the firm will receive the employment subsidy/tax $\Phi(x)$ independently of which worker type the firm employs.

Note that wages are also affected by the introduction of an employment subsidy/tax through its effect on the surplus of a match. The solution to the Nash bargaining problem is now given by

$$
w^{i}(x)=\eta\left(y^{i}(A)+\Phi(x)\right)+(1-\eta) \mathscr{O}^{i}(x)
$$

where $\mathscr{O}^{i}(x)$ is the worker's outside option defined by equations (23) and (24). It can be seen from the wage expression that in the presence of an employment subsidy $\Phi(x)>0$, wages are higher than in the absence of it. The positive effect of employment subsidies on wages has also been emphasized by Mortensen and Pissarides (2001).

\section{Equilibrium}

The surplus of a match with a high-skilled worker (equation (46)) and the vacancy creation equation (equation (47)) are given by

$$
\begin{gathered}
M_{s}^{H}(x)=A-b+\Phi(x)+\beta E_{x}\left\{(1-\gamma)\left(1-\eta p\left(\theta\left(x^{\prime}\right)\right)\right) M_{s}^{H}\left(x^{\prime}\right)+\eta p\left(\theta\left(x^{\prime}\right)\right) \delta A^{\prime}\right\} \\
\frac{\kappa}{q(\theta(x))}=(1-\eta)\left[M_{s}^{H}(x)-s(x) \delta A\right]
\end{gathered}
$$


Combining equation (46) and (47), job creation in the decentralized allocation in the presence of the employment subsidy is given by

$$
\frac{\kappa}{q(\theta(x))(1-\eta)}=\bar{y}(x)+\Phi(x)-b+\beta E_{x}\left\{\Lambda^{D}\left(x^{\prime}\right)\right\}
$$

where $\Lambda^{D}(x)$ is defined by equation (34) in section 3.2.

\section{A.4.2 Optimal Employment Subsidy/Tax}

The optimal employment subsidy/tax $\Phi(x)$ internalizes both the congestion and the composition externality if job creation in the decentralized allocation (equation (48)) replicates job creation in the constrained efficient allocation (equation (31)). It follows that the optimal employment subsidy/tax is given by

$$
\Phi(x)=\left[\begin{array}{c}
\frac{(\eta-\xi)}{(1-\xi)(1-\eta) q(\theta(x))} \kappa \\
+\beta E_{x}\left\{\frac{(\eta-\xi)(1-\gamma)\left(\eta p\left(\theta\left(x^{\prime}\right)\right)-1\right)}{(1-\xi)(1-\eta) q\left(\theta\left(x^{\prime}\right)\right)} \kappa+(1-\eta) p\left(\theta\left(x^{\prime}\right)\right)(1-(1-\gamma) s(n)) \delta A^{\prime}\right\}
\end{array}\right]
$$

\section{A.5 Multiple Equilibria}

Pissarides (1992) has shown that in an overlapping generations model where the unemployed are exposed to skill loss the steady state is not unique for certain parameter conditions. This finding has been confirmed by Coles and Masters (2000) in a different setup. The intuition behind this finding is that the expected gain from vacancy posting is no longer strictly decreasing in labour market tightness $\theta$. In an economy without skill erosion during unemployent, this gain is strictly decreasing in $\theta$ because the job filling probability is a decreasing function of $\theta$. In a model where skills erode, an increase in $\theta$ still implies a decrease in the job filling probability but there is an additional effect. Now an increase in $\theta$ also leads to an improvement in the skill distribution of the unemployment pool. The latter follows from a higher $\theta$ implying a lower average unemployment duration, and hence a smaller fraction of job-seekers with eroded skills. As pointed out by Pissarides (1992), when this effect is strong enough, an increase in $\theta$ can lead to an increase in the expected gain from vacancy posting, and hence multiple equilibria can arise.

Also in this model multiple steady state potentially arise. Evaluating the vacancy creation condition (33) in steady state shows that the expected gains are not necessarily strictly decreasing in $\theta$. However, for a reasonable parameterization, as described in section 5.1, the Blanchard-Kahn (1980) conditions are satisfied which implies that the model has a stable and unique solution. 


\section{A.6 Constrained-Efficient Allocation for General Case}

This section describes the constrained-efficient allocation when workers lose their skills with probability $0<l \leq 1$, and regain their skills upon reemployment with probability $0<g \leq 1$.

The constrained-efficient allocation is obtained by solving the social planner's problem. The latter is defined as

$V^{P}(x)=\max _{\theta}\left[y^{H}(A) n^{H}(x)+y^{L}(A) n^{L}(x)-\kappa \theta(x)\left(1-(1-\gamma) n\left(x_{-1}\right)\right)+b(1-n(x))+\beta E_{x}\left\{V^{P}\left(x^{\prime}\right)\right\}\right]$

subject to the law of motions of the endogenous state variables $\tilde{u}^{H}, \tilde{u}^{L}$ and $n^{L}$ (see equations (10), (11), and (12) respectively), and the process for aggregate technology (equation (1)), and where $n^{H}(x)=1-n^{L}(x)-\tilde{u}^{L}(x)-\tilde{u}^{H}(x) ; n=n^{H}(x)+n^{L}(x)$; and the economy's state is given by $x=$ $\left\{A, \tilde{u}_{-1}^{H}, \tilde{u}_{-1}^{L}, n_{-1}^{L}\right\}$.

The first order condition for vacancy creation is

$$
\frac{\kappa}{q(\theta(x))}=(1-\xi)\left[\bar{y}(x)-b+\beta E_{x}\left\{-(1-s(x)) \frac{\partial V^{P}\left(x^{\prime}\right)}{\partial \tilde{u}^{H}}-s(x) \frac{\partial V^{P}\left(x^{\prime}\right)}{\partial \tilde{u}^{L}}+s(x) \frac{\partial V^{P}\left(x^{\prime}\right)}{\partial n^{L}}\right\}\right]
$$

The envelope condition for high-skilled unemployment is

$$
\frac{\partial V^{P}(x)}{\partial \tilde{u}_{-1}^{H}}=\left\{\begin{array}{c}
-\underbrace{\left[(1-\gamma+\gamma p(\theta(x))) y^{H}(A)+\gamma(1-p(\theta(x))) \beta E_{x}\left\{\frac{\partial V^{P}\left(x^{\prime}\right)}{\partial \tilde{u}^{H}}\right\}\right]}_{\text {no HS worker }} \\
+\underbrace{p(\theta(x))}_{\text {hiring }}\left[(1-l) y^{H}(A)+l\left(y^{L}(A)+\beta E_{x}\left\{\frac{\partial V^{P}\left(x^{\prime}\right)}{\partial n^{L}}\right\}\right)\right] \\
+\underbrace{(1-p(\theta(x)))}_{\text {nohiring }} \beta E_{x}\left\{(1-l) \frac{\partial V^{P}\left(x^{\prime}\right)}{\partial \tilde{u}^{H}}+l \frac{\partial V^{P}\left(x^{\prime}\right)}{\partial \tilde{u}^{L}}\right\} \\
+(1-\gamma)(1-p(\theta(x))) b-(1-\gamma) \kappa \theta(x)
\end{array}\right\}
$$

The envelope condition for low-skilled unemployment is

$$
\frac{\partial V^{P}(x)}{\partial \tilde{u}_{-1}^{L}}=\left\{\begin{array}{c}
-\underbrace{\left[(1-\gamma+\gamma p(\theta(x))) y^{H}(A)+\gamma(1-p(\theta(x))) \beta E_{x}\left\{\frac{\partial V^{P}\left(x^{\prime}\right)}{\partial \tilde{u}^{H}}\right\}\right]}_{\text {hiring }} \\
+\underbrace{p(\theta(x))}_{\text {no HS worker }}\left[y^{L}(A)+\beta E_{x}\left\{\frac{\partial V^{P}\left(x^{\prime}\right)}{\partial n^{L}}\right\}\right]+\underbrace{(1-p(\theta(x)))}_{\text {no hiring }} \beta E_{x}\left\{\frac{\partial V^{P}\left(x^{\prime}\right)}{\partial \tilde{u}^{L}}\right\} \\
+(1-\gamma)(1-p(\theta(x))) b-(1-\gamma) \kappa \theta(x)
\end{array}\right\}
$$


The envelope condition for low-skilled employment is

$$
\frac{\partial V^{P}(x)}{\partial n_{-1}^{L}}=\underbrace{(1-g)}_{\text {no regaining }}\left\{\begin{array}{c}
-\underbrace{\left[(1-\gamma+\gamma p(\theta(x))) y^{H}(A)+\gamma(1-p(\theta(x))) \beta E_{x}\left\{\frac{\partial V^{P}\left(x^{\prime}\right)}{\partial \tilde{u}^{H}}\right\}\right]}_{\text {no HS worker }} \\
\left.+(1-\gamma+\gamma p(\theta(x)))\left[y^{L}(A)+\beta E_{x}\left\{\frac{\partial V^{P}\left(x^{\prime}\right)}{\partial n^{L}}\right\}\right]\right] \\
+\gamma(1-p(\theta(x))) \beta E_{x}\left\{\frac{\partial V^{P}\left(x^{\prime}\right)}{\partial \tilde{u}^{L}}\right\}
\end{array}\right\}
$$

The constrained-efficient allocation is defined by equations (50)-(53) together with the law of motions of the endogenous state variables (equations (10), (11), and (12)), and the process for aggregate technology (equation (1)).

\section{A.7 Economy with Separate Labour Markets for $g=l=1$}

\section{A.7.1 Labour Market}

The labour market is characterized by two separate markets: a market for workers with eroded skills and one for workers without. So workers' skill type determines the labour market in which they are searching. Firms can decide in which market they post vacancies. Each submarket is characterized by a specific matching technology. I define market 1 as the market for the high-skilled and market 2 as the market for the low-skilled. The matching function is assumed to be the same in both markets. The number of matches in each submarket $k=\{1,2\}$ is given by

$$
m_{k}=B v_{k}^{1-\xi} u_{k}^{\xi}
$$

Defining labour market tightness $\theta_{k}(x) \equiv \frac{v_{k}(x)}{u_{k}(x)}$ the job finding probability, and the job filling probability are given by

$$
\begin{gathered}
q\left(\theta_{k}(x)\right) \equiv \frac{m\left(v_{k}(x), u_{k}(x)\right)}{v_{k}(x)}=B \theta_{k}(x)^{-\xi} \\
p\left(\theta_{k}(x)\right) \equiv \frac{m\left(v_{k}(x), u_{k}(x)\right)}{u_{k}(x)}=B \theta_{k}(x)^{1-\xi}
\end{gathered}
$$

where $x=\{A\}$ is the economy's state. The latter is only a function of aggregate technology just as in the standard model because each submarket $i$ contains only one type of unemployed.

Timing. The timing is the same as outlined in section 2.2.

Labour market flows.

Job-seekers in submarket 1

$$
u_{1}=\gamma n\left(x_{-1}\right)
$$


Job-seekers in submarket 2

$$
u_{2}=1-n\left(x_{-1}\right)
$$

High-skilled employment

$$
n^{H}(x)=(1-\gamma) n\left(x_{-1}\right)+p\left(\theta_{1}(x)\right) u_{1}
$$

Low-skilled employment

$$
n^{L}(x)=p\left(\theta_{2}(x)\right) u_{2}
$$

Total employment

$$
n(x)=(1-\gamma) n\left(x_{-1}\right)+p\left(\theta_{1}(x)\right) u_{1}+p\left(\theta_{2}(x)\right) u_{2}
$$

The labour market flows show that in the presence of skill erosion during unemployment and learning-by-doing there is an interaction between both submarkets. The number of job-seekers in submarket 2 will not only depend on the amount of jobs created in the previous period in this submarket but also on the amount of jobs that was created in submarket 1 . The reason is that workers who did not get hired in submarket 1 , lose a fraction of their skills and become job-seekers in submarket 2 .

\section{A.7.2 Decentralized Allocation}

\section{Firm's problem}

The value from having a worker of type $i=\{H, L\}$ producing is given by

$$
J^{i}(x)=y^{i}(x)-w^{i}(x)+(1-\gamma) \beta E_{x}\left\{J^{H}\left(x^{\prime}\right)\right\}
$$

The value from having a vacancy in submarket 1 is given by

$$
V_{1}(x)=-\kappa+q\left(\theta_{1}(x)\right) J^{H}(x)+\left(1-q\left(\theta_{1}(x)\right)\right) \beta E_{x}\left\{V_{1}\left(x^{\prime}\right)\right\}
$$

The value from having a vacancy in submarket 2 is given by

$$
V_{2}(x)=-\kappa+q\left(\theta_{2}(x)\right) J^{H}(x)+\left(1-q\left(\theta_{2}(x)\right)\right) \beta E_{x}\left\{V_{2}\left(x^{\prime}\right)\right\}
$$

Free-entry in both submarkets implies

$$
V_{1}(x)=V_{2}(x)=0
$$

Note that the value from being in a match only depends on the expected hiring cost, and no longer on the unemployment pool's composition: $J^{H}(x)=\frac{\kappa}{q\left(\theta_{1}(x)\right)}$ and $J^{L}(x)=\frac{\kappa}{q\left(\theta_{2}(x)\right)}$. The reason is that 
by posting a vacancy firms will be able to hire a worker of the same type, because the unemployment pool in each submarket is homogeneous.

\section{Worker's problem}

The value from being employed as type $i=\{H, L\}$ is given by

$$
W^{i}(x)=w^{i}(x)+\beta E_{x}\left\{\left(1-\gamma+\gamma p\left(\theta_{1}\left(x^{\prime}\right)\right)\right) W^{H}\left(x^{\prime}\right)+\gamma\left(1-p\left(\theta_{1}\left(x^{\prime}\right)\right)\right) U\left(x^{\prime}\right)\right\}
$$

The value from being unemployed is given by

$$
U(x)=b+\beta E_{x}\left\{p\left(\theta_{2}\left(x^{\prime}\right)\right) W^{L}\left(x^{\prime}\right)+\left(1-p\left(\theta_{2}\left(x^{\prime}\right)\right)\right) U\left(x^{\prime}\right)\right\}
$$

The worker's surplus from being in a match becomes

$$
X^{i}(x)=w^{i}(x)-\mathscr{O}(x)+(1-\gamma) \beta E_{x}\left\{X^{H}\left(x^{\prime}\right)\right\}
$$

where $\mathscr{O}(x)$ represents the worker's outside option

$$
\mathscr{O}(x) \equiv b+\beta E_{x}\left\{p\left(\theta_{2}\left(x^{\prime}\right)\right) X^{L}\left(x^{\prime}\right)-\gamma p\left(\theta_{1}\left(x^{\prime}\right)\right) X^{H}\left(x^{\prime}\right)\right\}
$$

Wages

Wages are determined through Nash bargaining between workers and firms in every period. When workers' bargaining power in submarket $k$ is given by $\eta_{k}$, Nash bargaining implies

$$
\begin{gathered}
X^{H}(x)=\eta_{1} M^{H}(x) \\
J^{H}(x)=\left(1-\eta_{1}\right) M^{H}(x) \\
X^{L}(x)=\eta_{2} M^{L}(x) \\
J^{L}(x)=\left(1-\eta_{2}\right) M^{L}(x)
\end{gathered}
$$

where $M^{i}(x) \equiv X^{i}(x)+J^{i}(x)$ represents the surplus of being in a match with a worker of type $i$. The solution to the Nash bargaining problem results in the following expressions for the wage of a high-skilled and low-skilled worker respectively

$$
\begin{gathered}
w^{H}(x)=\eta_{1} y^{H}(x)+\left(1-\eta_{1}\right) \mathscr{O}(x) \\
w^{L}(x)=\eta_{2} y^{L}(x)+\left(1-\eta_{2}\right) \mathscr{O}(x)+(1-\gamma) \beta E_{x}\left\{\eta_{2} J^{H}\left(x^{\prime}\right)-\left(1-\eta_{2}\right) X^{H}\left(x^{\prime}\right)\right\}
\end{gathered}
$$

Equilibrium

Submarket 1

$$
\frac{\kappa}{q\left(\theta_{1}(x)\right)}=\left(1-\eta_{1}\right) M^{H}(x)
$$




$$
M^{H}(x)=y^{H}(x)-b+\beta E_{x}\left\{\left[1-\gamma+\eta_{1} \gamma p\left(\theta_{1}\left(x^{\prime}\right)\right)\right] M^{H}\left(x^{\prime}\right)-\eta_{2} p\left(\theta_{2}\left(x^{\prime}\right)\right) M^{L}\left(x^{\prime}\right)\right\}
$$

Combining both equations gives

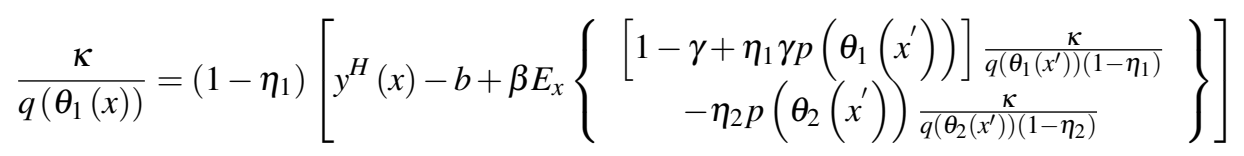

Submarket 2

$$
\begin{gathered}
\frac{\kappa}{q\left(\theta_{2}(x)\right)}=\left(1-\eta_{2}\right) M^{L}(x) \\
M^{L}(x)=y^{L}(x)-b+\beta E_{x}\left\{\left[1-\gamma+\eta_{1} \gamma p\left(\theta_{1}\left(x^{\prime}\right)\right)\right] M^{H}\left(x^{\prime}\right)-\eta_{2} p\left(\theta_{2}\left(x^{\prime}\right)\right) M^{L}\left(x^{\prime}\right)\right\}
\end{gathered}
$$

Combining both equations gives

$$
\frac{\kappa}{q\left(\theta_{2}(x)\right)}=\left(1-\eta_{2}\right)\left[y^{L}(x)-b+\beta E_{x}\left\{\begin{array}{c}
{\left[1-\gamma+\eta_{1} \gamma p\left(\theta_{1}\left(x^{\prime}\right)\right)\right] \frac{\kappa}{q\left(\theta_{1}\left(x^{\prime}\right)\right)\left(1-\eta_{1}\right)}} \\
-\eta_{2} p\left(\theta_{2}\left(x^{\prime}\right)\right) \frac{\kappa}{q\left(\theta_{2}\left(x^{\prime}\right)\right)\left(1-\eta_{2}\right)}
\end{array}\right\}\right]
$$

\section{A.7.3 Constrained-Efficient Allocation}

The social planner's problem consists of choosing labour market tightness in both submarkets such that total output in the economy, net of vacancy posting costs, is maximized. The planner's problem is given by

$$
V^{P}\left(x^{P}\right)=\max _{\theta_{1}, \theta_{2}}\left[\begin{array}{c}
y^{H}(A) n^{H}\left(x^{P}\right)+y^{L}(A) n^{L}\left(x^{P}\right)-\kappa \theta_{1}\left(x^{P}\right) \gamma n_{-1} \\
-\kappa \theta_{1}\left(x^{P}\right)\left(1-n_{-1}\right)+b(1-n)+\beta E_{x^{P}}\left\{V^{P}\left(x^{P \prime}\right)\right\}
\end{array}\right]
$$

with $n^{H}\left(x^{P}\right)=(1-\gamma) n_{-1}+B \theta_{1}\left(x^{P}\right)^{1-\xi} \gamma n_{-1}$ and $n^{L}\left(x^{P}\right)=B \theta_{2}\left(x^{P}\right)^{1-\xi}\left(1-n_{-1}\right)$ and subject to the law of motion for employment

$$
n=(1-\gamma) n_{-1}+B \theta_{1}\left(x^{P}\right)^{1-\xi} \gamma n_{-1}+B \theta_{2}\left(x^{P}\right)^{1-\xi}\left(1-n_{-1}\right)
$$

The relevant state for the social planner is given by $x^{P}=\left\{A, n_{-1}\right\}$.

The first order condition for labour market tightness in submarket 1 and 2 are respectively given by

$$
\begin{aligned}
& \frac{\kappa}{q\left(\theta_{1}\left(x^{P}\right)\right)}=(1-\xi)\left[y^{H}(A)-b+\beta E_{x^{P}}\left\{\frac{\partial V^{P}\left(x^{P \prime}\right)}{\partial n}\right\}\right] \\
& \frac{\kappa}{q\left(\theta_{2}\left(x^{P}\right)\right)}=(1-\xi)\left[y^{L}(A)-b+\beta E_{x^{P}}\left\{\frac{\partial V^{P}\left(x^{P \prime}\right)}{\partial n}\right\}\right]
\end{aligned}
$$

The envelope condition for employment is given by 


$$
\frac{\partial V^{P}\left(x^{P}\right)}{\partial n_{-1}}=\left[\begin{array}{c}
{\left[1-\gamma+\gamma p\left(\theta_{1}\left(x^{P}\right)\right)\right] y^{H}(A)-p\left(\theta_{2}\left(x^{P}\right)\right) y^{L}(A)+\kappa\left(\theta_{2}\left(x^{P}\right)-\gamma \theta_{1}\left(x^{P}\right)\right)} \\
-\left[1-\gamma+\gamma p\left(\theta_{1}\left(x^{P}\right)\right)-p\left(\theta_{2}\left(x^{P}\right)\right)\right]\left[b-\beta E_{x^{P}}\left\{\frac{\partial V^{P}\left(x^{P \prime}\right)}{\partial n}\right\}\right]
\end{array}\right]
$$

Combining the first order condition for submarket $i$ with the envelope condition, gives the following expressions for job creation in each submarket

Submarket 1

$$
\frac{\kappa}{q\left(\theta_{1}\left(x^{P}\right)\right)}=(1-\xi)\left[y^{H}(A)-b+\beta E_{x^{P}}\left\{\begin{array}{c}
{\left[1-\gamma+\xi \gamma p\left(\theta_{1}\left(x^{P \prime}\right)\right)\right] \frac{\kappa}{q\left(\theta_{1}\left(x^{P \prime}\right)\right)(1-\xi)}} \\
-\xi p\left(\theta_{2}\left(x^{P \prime}\right)\right) \frac{\kappa}{q\left(\theta_{2}\left(x^{P \prime}\right)\right)(1-\xi)}
\end{array}\right\}\right]
$$

Submarket 2

$$
\frac{\kappa}{q\left(\theta_{2}\left(x^{P}\right)\right)}=(1-\xi)\left[y^{L}(A)-b+\beta E_{x^{P}}\left\{\begin{array}{c}
{\left[1-\gamma+\xi \gamma p\left(\theta_{1}\left(x^{P \prime}\right)\right)\right] \frac{\kappa}{q\left(\theta_{1}\left(x^{P \prime}\right)\right)(1-\xi)}} \\
-\xi p\left(\theta_{2}\left(x^{P \prime}\right)\right) \frac{\kappa}{q\left(\theta_{2}\left(x^{P \prime}\right)\right)(1-\xi)}
\end{array}\right\}\right]
$$

Note that labour market tightness in each submarket is such that

$$
\frac{\kappa}{q\left(\theta_{2}\left(x^{P}\right)\right)(1-\xi)}=\frac{\kappa}{q\left(\theta_{1}\left(x^{P}\right)\right)(1-\xi)}-\left[y^{H}(A)-y^{L}(A)\right]
$$

This implies that even though it is equally costly to post vacancies in submarket 1 , in equilibrium labour market tightness is higher in submarket 1 because there is an output gain $\delta A$ related to posting in this submarket relative to posting in submarket 2 .

\section{A.8 Proof of Proposition 4}

Proof. Comparing equations (54) and (55) with equations (56) and (57), shows that the decentralized allocation is constrained-efficient if the standard Hosios condition is satisfied in each submarket. 